\title{
High Cycle Fatigue of Cast Mg-3Nd-0.2Zn Magnesium Alloys
}

\author{
ZHENMING LI, QIGUI WANG, ALAN A. LUO, PENGHUAI FU, LIMING PENG, \\ YINGXIN WANG, and GUOHUA WU
}

\begin{abstract}
This paper investigates the high cycle fatigue properties of a recently developed high-strength cast magnesium alloy [Mg-3Nd-0.2Zn (all compositions in wt pct except when otherwise stated)] with varied $\mathrm{Zr}$ contents for grain refinement $(\mathrm{NZ30K})$ and the influence of heat treatment conditions. The NZ30K alloy containing $0.45 \mathrm{Zr}$ and heat treated to the peak-aged $\mathrm{T} 6$ condition [14 hours at $473 \mathrm{~K}\left(200{ }^{\circ} \mathrm{C}\right)$ ] shows the highest fatigue strength, about $100 \mathrm{MPa}$, which is about 25 pct higher than that of commercial AZ91D-T6 alloy. In the absence of casting flaws, the high cycle fatigue properties of the NZ30K alloy strongly depend on its grain size and heat treatment conditions. The dependency of fatigue strength on grain sizes follows the Hall-Petch relationship. The NZ30K alloy also shows a significant response to heat treatments. The fatigue strength increases in a near linear fashion with increasing yield strength of the material through heat treatment.
\end{abstract}

DOI: $10.1007 / \mathrm{s} 11661-013-1843-3$

(C) The Minerals, Metals \& Materials Society and ASM International 2013

\section{INTRODUCTION}

CAST magnesium alloys are increasingly used in automotive, aerospace, and other transportation industries due to their low density, high strength to weight ratio, and good castability compared with other structural materials. ${ }^{[1,2]}$ As many structural applications such as automotive engine blocks and engine cradles involve cyclic loading, it is very important to understand the fatigue behavior of these alloys. Fatigue properties of cast components strongly depend on casting flaws and microstructural characteristics. ${ }^{[3]}$ The castings generally demonstrate easy fatigue crack initiation due to the presence of casting flaws such as porosity and oxides at or below the casting surface. ${ }^{[4,5]}$ In addition to casting defects, the fatigue and fracture properties of cast alloys also strongly depend on the microstructure including grain size and second-phase particles and precipitates, which are determined by their composition, casting, and heat treatment conditions. ${ }^{[-7]}$ An extensive understanding of the role of microstructural constituents on fatigue properties of $\mathrm{Mg}$ castings is lacking and is extremely important particularly when magnesium alloys are expected to be increasingly used in structural components.

NZ30K (Mg-3Nd-0.2Zn with minor additions of $\mathrm{Zr}$ as grain refiner) is a recently developed magnesium alloy ${ }^{[7]}$ which offers high strength and ductility as well as good creep resistance; thus, it is very attractive to

ZHENMING LI, Ph.D. Student, PENGHUAI FU and YINGXIN WANG, Assistant Researchers, LIMING PENG and GUOHUA WU, Professors, are with the National Engineering Research Center of Light Alloys Net Forming and State Key Laboratory of Metal Matrix Composite, Shanghai Jiao Tong University, Shanghai 200240, People's Republic of China. Contact e-mail: plm616@sjtu.edu.cn QIGUI WANG, Materials Technical Specialist-Process \& Property Modeling and Optimization, and ALAN A. LUO, Technical Fellow, are with General Motors, Warren, MI 48090.

Manuscript submitted January 3, 2013.

Article published online June 29, 2013 automotive powertrain and structural applications. The NZ30K alloy has been used in low pressure sand cast (LPSC) V6 engine blocks. The microstructure of the as-cast NZ30K alloy comprises magnesium matrix and $\mathrm{Mg}_{12} \mathrm{Nd}$ eutectic compounds. It has been reported that the cast NZ30K alloy can achieve high yield and ultimate tensile strength at room temperature with proper heat treatment. ${ }^{[7-9]}$ Different aging treatments were shown to lead to different precipitates in the microstructure. ${ }^{[7]}$ At the peak-aged condition (T6-PA: 10 to 16 hours at $\left.473 \mathrm{~K}\left(200{ }^{\circ} \mathrm{C}\right)\right)$, fine $\beta^{\prime \prime}$ particles with $\mathrm{DO}_{19}$ structure $(a=0.64 \mathrm{~nm}, c=0.52 \mathrm{~nm})$ are the dominant strengthening phase, while $\beta^{\prime}$ precipitates of fcc structure $(a=0.742 \mathrm{~nm})$ are the dominant phase when the alloy is aged at $523 \mathrm{~K}\left(250^{\circ} \mathrm{C}\right)$ for 10 hours (T62-OA) ${ }^{[7,8]}$ However, no comprehensive study of the effect of heat treatment on the fatigue properties of this alloy without defects is yet reported. Furthermore, the effectiveness of grain refinement using $\mathrm{Zr}$ during remelting of this alloy is strongly subjected to the melting process and initial content of $\mathrm{Zr}$ addition. Hence, it is necessary to understand the effect of grain size on fatigue properties of this alloy so as to widen practical applications of this casting alloy. This research was conducted to study the effects of zirconium ( $\mathrm{Zr}$ ) addition (for grain refinement) and heat treatment conditions on the fatigue properties and fracture behavior of the NZ30K alloy. A commercial AZ91D-T6 alloy is also included as a baseline in this study.

\section{EXPERIMENTAL PROCEDURE}

\section{A. Alloys and Casting}

The materials used in this work were gravity permanent mold (PM) castings of NZ30K (Mg-3Nd-0.2Zn- $x \mathrm{Zr})$ alloy, as shown in Figure 1(a). Samples $(\phi 13 \times$ $130 \mathrm{~mm}^{2}$ ) for fatigue testing were sectioned from the 
PM castings, as shown in Figure 1(b). Alloys with nominal compositions of $\mathrm{Mg}-3 \mathrm{Nd}-0.2 \mathrm{Zn}-x \mathrm{Zr}(x=0$, $0.1,0.3,0.5,1.0,2.0)$, designated as NZ30, NZ30K01, NZ30K03, NZ30K05, NZ30K1, and NZ30K2, respectively, were prepared using high-purity $\mathrm{Mg}, \mathrm{Zn}$, and $\mathrm{Mg}-25 \mathrm{Nd}, \mathrm{Mg}-30 \mathrm{Zr}$ master alloys in an electrical resistance furnace under atmosphere protection with a gas mixture of $\mathrm{SF}_{6}, \mathrm{CO}_{2}$, and air. The castings were made at a pouring temperature of $1013 \pm 5 \mathrm{~K}(740 \pm$ $5{ }^{\circ} \mathrm{C}$ ) and a steel mold pre-heated to $473 \pm 5 \mathrm{~K}$ $\left(200 \pm 5{ }^{\circ} \mathrm{C}\right)$. The actual chemical compositions of the alloys were determined using the inductively coupled plasma (ICP) technique, and the results are listed in Table I. Specimens of AZ91D (Mg-8.6Al-0.7Zn-0.2Mn) alloy were prepared in the same conditions and included as a baseline for comparison.

\section{B. Heat Treatment}

After casting, the fatigue specimens were first solutionized at $813 \mathrm{~K}\left(540{ }^{\circ} \mathrm{C}\right)$ for 10 hours, quenched into hot water at $343 \mathrm{~K}\left(70{ }^{\circ} \mathrm{C}\right)$ (designated as T4), and then aged to different aging conditions. The T6-PA treatment (peak-aged at $473 \mathrm{~K}\left(200{ }^{\circ} \mathrm{C}\right)$ for 14 hours) was applied to a group of the solutionized samples for each alloy composition (i.e., different $\mathrm{Zr}$ contents). Additionally, based on the aging hardness curves of NZ30K alloy isothermally aged at $473 \mathrm{~K}$ and $523 \mathrm{~K}\left(200{ }^{\circ} \mathrm{C}\right.$ and $250{ }^{\circ} \mathrm{C}$ ) as reported earlier, ${ }^{[7]}$ T6-UA [under-aging at $473 \mathrm{~K}\left(200^{\circ} \mathrm{C}\right)$ for 4 hours], T6-PA [peak-aging at
$473 \mathrm{~K}\left(200{ }^{\circ} \mathrm{C}\right)$ for 14 hours], T6-OA [over-aging at $473 \mathrm{~K}\left(200^{\circ} \mathrm{C}\right)$ for 128 hours], and T62-OA [over-aging at $523 \mathrm{~K}\left(250{ }^{\circ} \mathrm{C}\right)$ for 10 hours] were applied to four groups of NZ30K1 (Mg-3Nd-0.2Zn-1.0Zr) alloy samples, as shown in Figure 2. The samples of AZ91D alloy were heat treated at $688 \mathrm{~K}\left(415^{\circ} \mathrm{C}\right)$ for 8 hours and aged at $453 \mathrm{~K}\left(180{ }^{\circ} \mathrm{C}\right)$ for 24 hours.

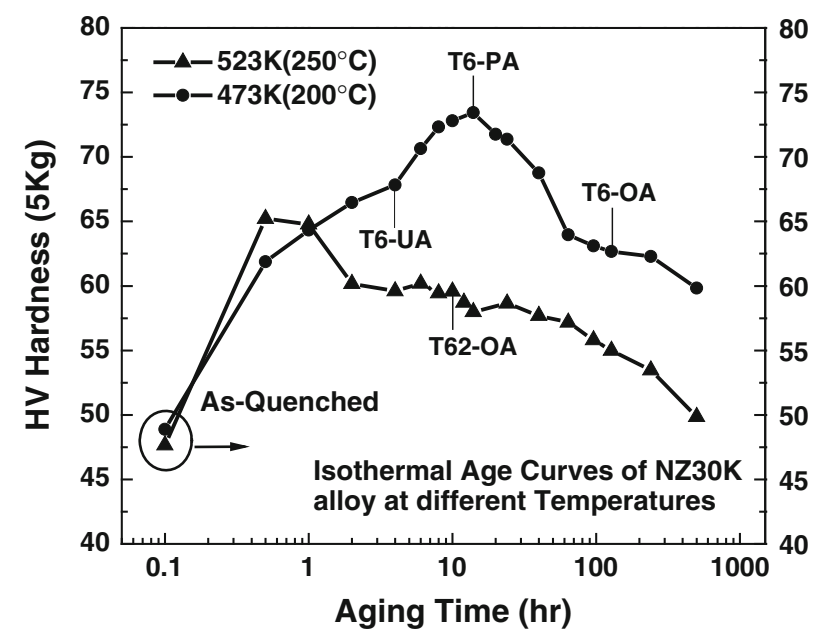

Fig. 2-Hardness evolution as a function of aging time during isothermal aging at $473 \mathrm{~K}$ and $523 \mathrm{~K}\left(200^{\circ} \mathrm{C} \text { and } 250{ }^{\circ} \mathrm{C}\right)^{[7]}$.

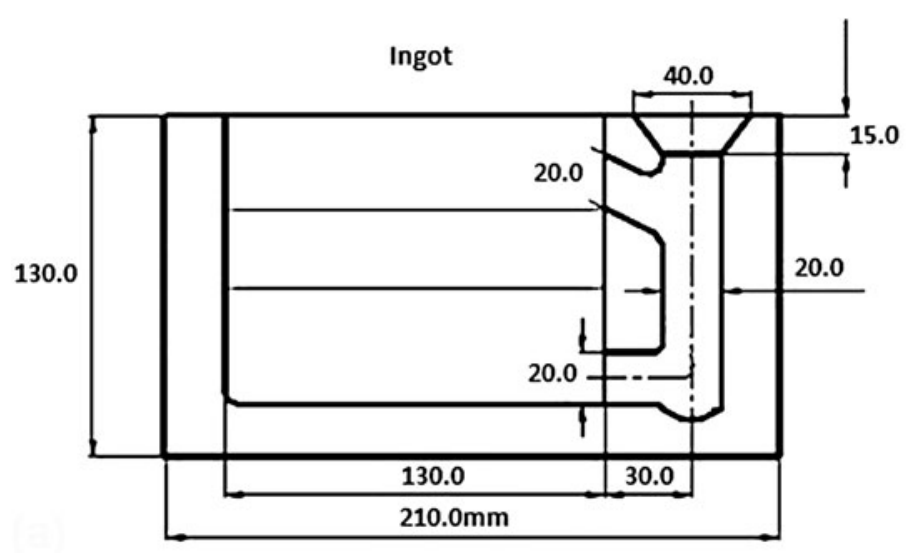

(a)

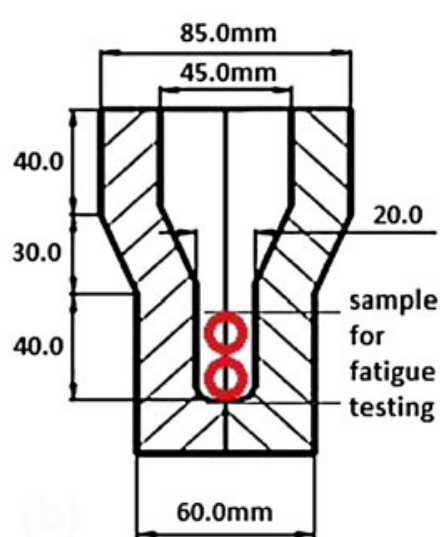

(b)

Fig. 1-(a) Permanent mold casting ingot and (b) sampling locations for fatigue specimens.

Table I. Chemical Composition of NZ30K Alloys (Weight Percentage)

\begin{tabular}{lcccccc}
\hline & \multicolumn{5}{c}{ Alloy } \\
\cline { 2 - 6 } Element & NZ30 & NZ30K01 & NZ30K03 & NZ30K05 & NZ30K1 & NZ30K2 \\
\hline $\mathrm{Zr}$ & 0 & 0.003 & 0.05 & 0.10 & 0.45 & 0.50 \\
$\mathrm{Nd}$ & 2.98 & 2.99 & 2.97 & 3.10 & 2.96 & 0.18 \\
$\mathrm{Zn}$ & 0.19 & 0.20 & 0.21 & bal. & bal. \\
$\mathrm{Mg}$ & bal. & bal. & bal. & bal. \\
\hline
\end{tabular}




\section{Microstructural and Fractographic Analyses}

The microstructure of the alloys was examined with an optical microscope (OM) and quantified in terms of grain sizes. Specimens for microstructural analysis (taken from the grip areas of the fatigue samples) were polished and then etched using $4 \mathrm{vol}$ pct nital (a solution of $20 \mathrm{~mL}$ acetic acid $+60 \mathrm{~mL}$ ethanol $+1 \mathrm{~mL}$ nitric acid $+19 \mathrm{~mL}$ water). The average grain sizes of the alloys were measured using a linear intercept method

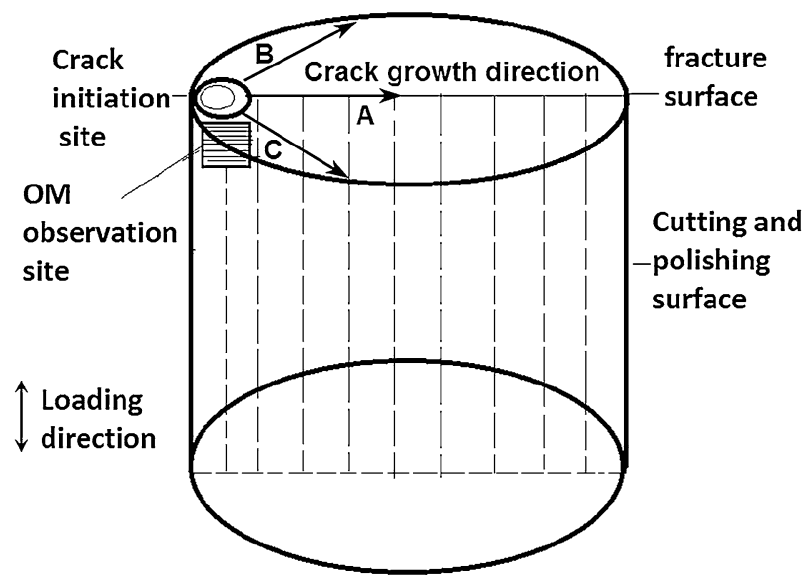

Fig. 3-Schematic illustration of OM observation of the specimen sectioned longitudinally along the sample axial direction. and at least 400 grain boundaries were counted for each alloy sample. Fracture surfaces were investigated with a scanning electron microscope (SEM). In order to investigate the fatigue crack initiation and propagation behavior, some failed samples were sectioned longitudinally along the sample axial direction and observed with $\mathrm{OM}$, as shown in Figure 3.

\section{Fatigue Testing}

Hourglass-shaped round specimens, with a minimum gage diameter of $6 \mathrm{~mm}$ according to ASTM E466 specification, were used for fatigue testing. The gage surfaces of all fatigue specimens were polished parallel to the specimen axis using abrasive paper of grit 1600 and then buff-polished to avoid the influence of machining on the fatigue results. Fatigue testing was performed under rotating beam loading $(R=-1)$ at a frequency of about $100 \mathrm{~Hz}$ in ambient air [temperature of $298 \mathrm{~K}$ to $308 \mathrm{~K}\left(25^{\circ} \mathrm{C}\right.$ to $\left.35^{\circ} \mathrm{C}\right)$, relative humidity of 40 to $60 \mathrm{pct}$. The load-controlled staircase (SC) fatigue test was adopted to estimate the mean and standard deviation of fatigue strength at a given number $\left(10^{7}\right)$ of cycles to failure. ${ }^{[10]}$ The procedure for SC testing for fatigue strength is provided in Reference 10 and methods of computing the mean and standard deviation of fatigue strength are shown in Formulas [1] to [3] below. The tests were conducted in such a way that if no failure occurred after $10^{7}$ cycles under the former stress
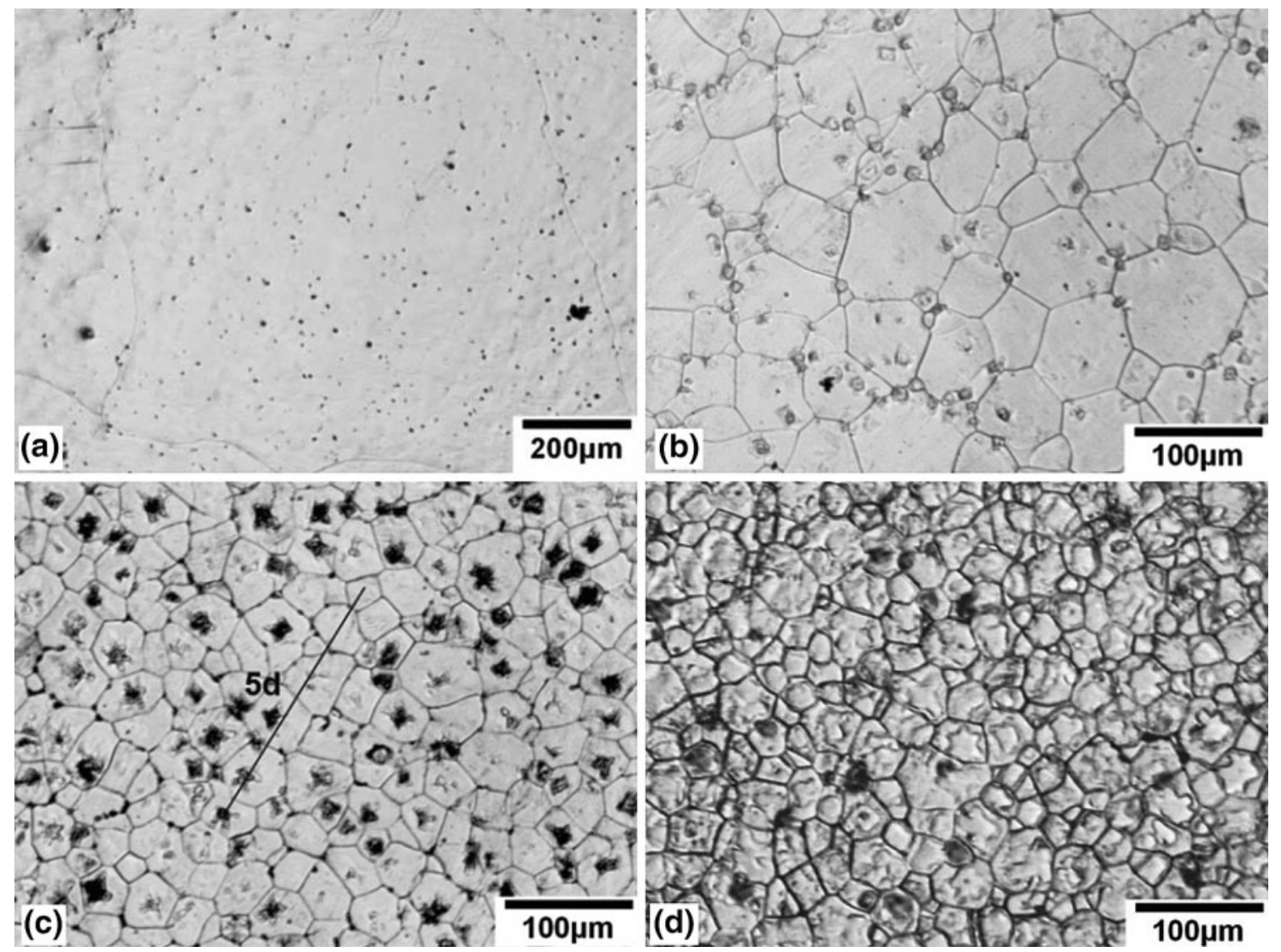

Fig. 4 -Optical micrographs of the NZ30K-T6-PA alloys: (a) NZ30K01, (b) NZ30K1, and (c) NZ30K2. The way in which grain sizes are measured is shown in (c). The micrograph of as-cast NZ30K2 alloy is also included in $(d)$ for comparison. 
level, the maximum stress level was successively increased by $5 \mathrm{MPa}$ until specimen failure occurred; on the contrary, if failure occurred before $10^{7}$ cycles, the maximum stress level was successively decreased by $5 \mathrm{MPa}$ until specimen failure occurred. 20 to 25 samples were used for each group test in this study.

$$
\text { Mean fatigue strength }=\sigma_{0}+d\left[\left(\sum\left(i N_{i}\right) / n\right)+b\right], \quad[1]
$$$$
\text { Standard deviation }=1.63 d(C+0.029) \text {, }
$$

$C=\left[\left(n * \sum\left(i^{2} N_{i}\right)\right)-\left(\sum\left(i N_{i}\right)^{2}\right)\right] / n^{2}$

$$
\text { ( } C \geq 0.30 \text { for valid standard deviation), }
$$

where $\sigma_{0}$ is the lowest stress level; $d$ the step size; $N_{i}$ the number of runouts or failures (whichever is lower) at each stress level $i ; i=0$ for the lowest stress level, 1 for the next lowest, etc.; $n$ the total number of runouts or failures; $b=+1 / 2$ for runouts and $-1 / 2$ for failures; and $C$ is the convergence factor. If $C<0.3$, a valid standard deviation cannot be calculated. This occurs when the step size is large enough that the test oscillates between failures at one stress amplitude and runouts at another. In this case, an acceptable estimate for standard deviation is 0.75 times the step size.

\section{RESULTS}

\section{A. Effect of $\mathrm{Zr}$ Content on the Grain Size}

Figure 4 shows typical microstructures of the NZ30K-T6-PA alloy with different grain sizes. When

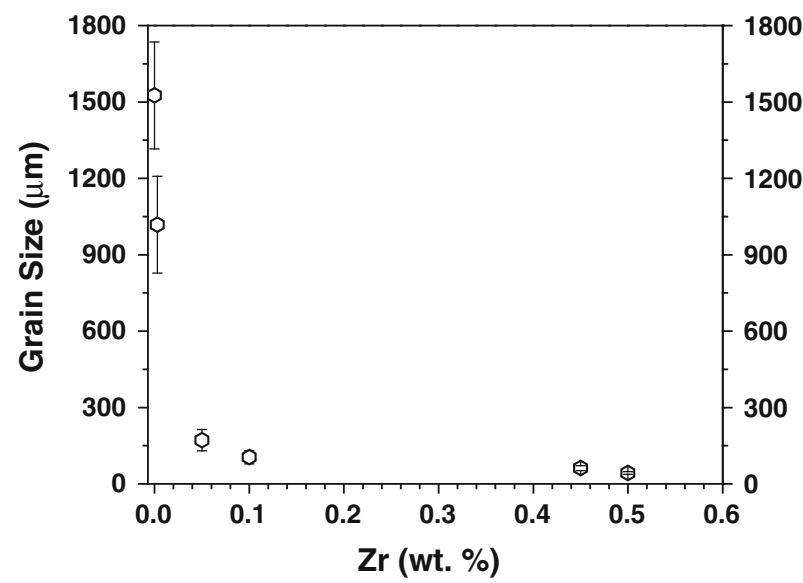

Fig. 5-The relationship between the $\mathrm{Zr}$ concentration in $\alpha-\mathrm{Mg}$ and the grain sizes of the NZ30K-T6-PA alloys. The error bars represent $\pm 1 \mathrm{SD}$.
$\mathrm{Zr}$ content is high ( $>0.40 \mathrm{wt}$ pct), Zr-containing particles $^{[11]}$ are observed in the microstructure, as shown in Figure 4(c). However, the effect of these particles on fatigue strength is neglected here due to their small size and low volume fraction. ${ }^{[1]}$ The micrograph of as-cast $\mathrm{NZ30K} 2$ alloy (Mg-3Nd-0.2Zn-2Zr) with finer grains is also included in Figure 4(d) for comparison. For many Zr-refined rare earth-containing $\mathrm{Mg}$ alloys, significant grain coarsening occurs during T4 and T6 treatment. However, for the NZ30K alloys, the grains do not coarsen during heat treatment, as shown in Figures 4(c) and (d). Figure 5 shows that the grain size decreases with the increasing $\mathrm{Zr}$ content, with the sharpest decrease occurring at $\mathrm{Zr}$ contents up to about 0.05 pct. The mean grain size is reduced from near $1.5 \mathrm{~mm}$ to about $150 \mu \mathrm{m}$ (as listed in Table II). Further increase of $\mathrm{Zr}$ content beyond 0.1 pct does not significantly reduce the average grain size, but the microstructure becomes more uniform (Figures 4(c) and 6). Figure 6 shows that the typical grain size distribution is close to Gaussian distribution.

\section{B. Effect of Grain Size on the Fatigue Strength of NZ30K Alloy}

The fatigue test results of the NZ30K alloy with different grain sizes are shown in Figure 7, while Table III shows tensile properties of the NZ30K alloy for different grain sizes. The ratios of the fatigue strength to yield strength $\left(\sigma_{\mathrm{f}} / \sigma_{0.2}\right)$ of the NZ30K alloy are summarized in Figure 8. As shown in Figures 7 and 8 , the fatigue strength $\left(\mathrm{FS}-\sigma_{\mathrm{f}}\right)$ of the solution-treated

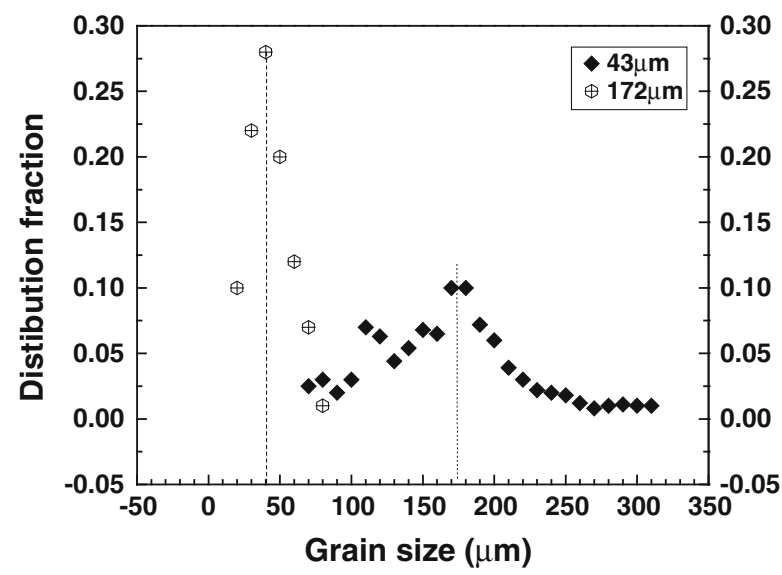

Fig. 6-Two groups of grain size distributions in the NZ30K-T6-PA alloys (avg. grain size: $172 \mu \mathrm{m}$ and avg. grain size: $43 \mu \mathrm{m}$ ). The distribution fraction of grain sizes in the NZ30K alloys are close to Gaussian distribution.

Table II. Average Grain Sizes of NZ30K-T6-PA Alloys

\begin{tabular}{lrcrrrr}
\hline & \multicolumn{3}{c}{ Alloy } \\
\cline { 2 - 7 } & NZ30 & NZ30K01 & NZ30K03 & NZ30K05 & NZ30K1 & NZ30K2 \\
\hline Grain size $(\mu \mathrm{m})$ & 1526 & 1018 & 172 & 105 & 62 & 43 \\
Standard deviation $(\mu \mathrm{m})$ & 210 & 190 & 42 & 26 & 10 & 5 \\
\hline
\end{tabular}




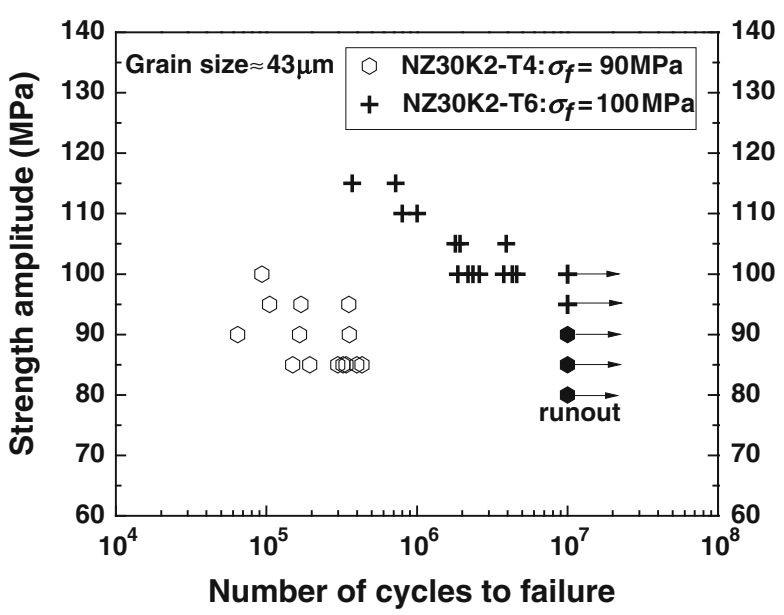

(a)

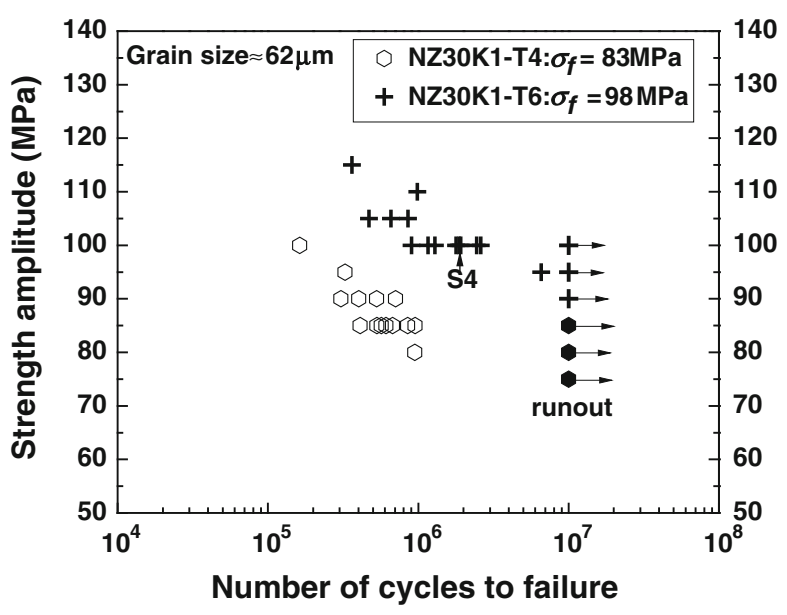

(b)

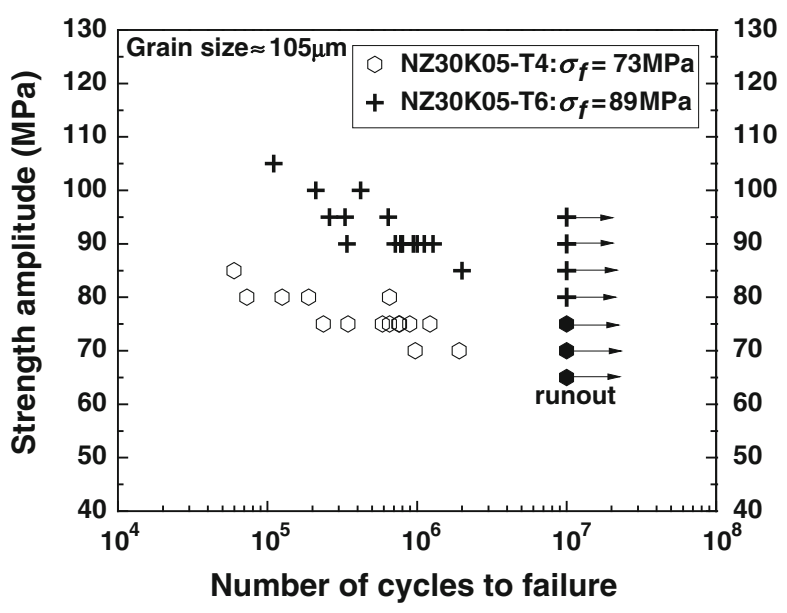

(c)

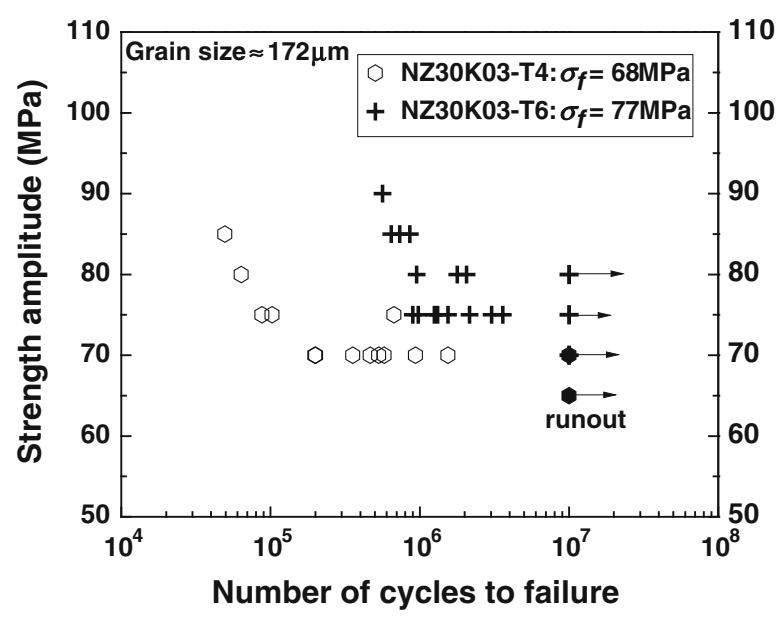

(d)

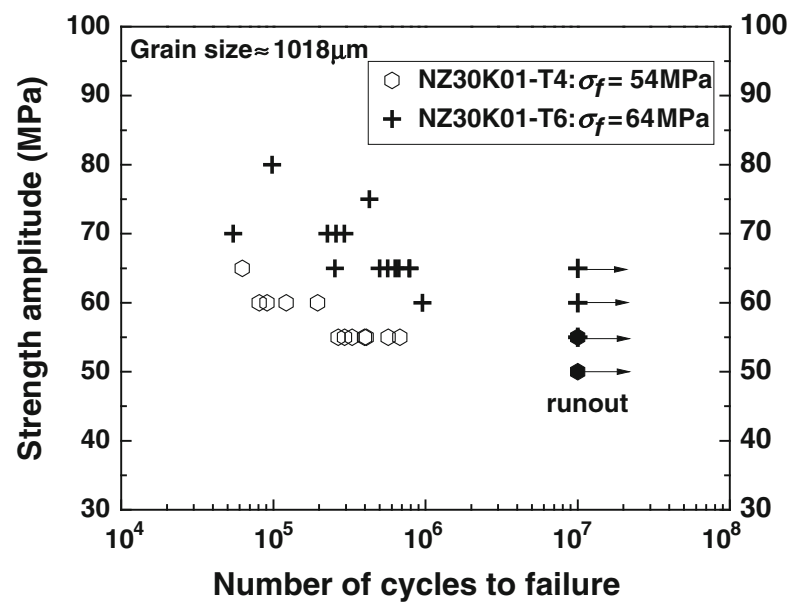

(e)

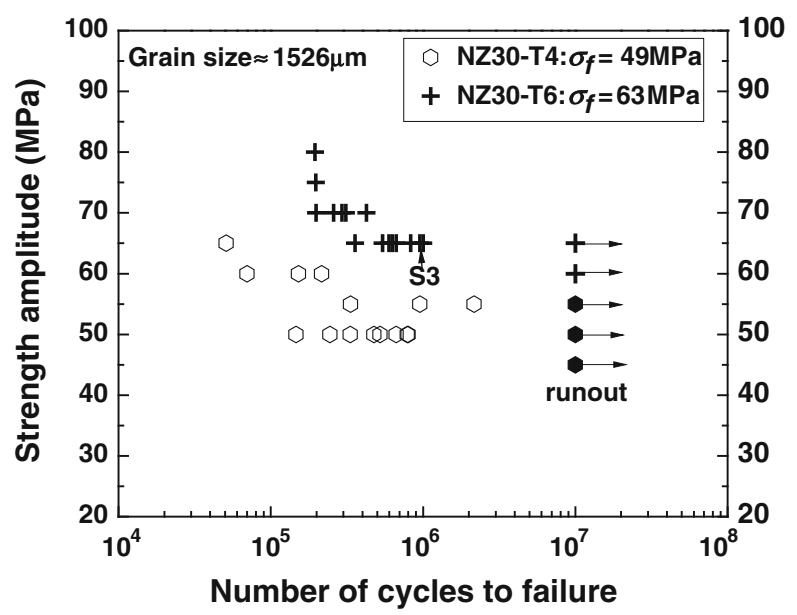

(f)

Fig. 7- Stress-life curves of NZ30K alloys with different grain sizes, both T4 and T6 conditions: (a) NZ30K2-43 $\mu \mathrm{m}$, (b) NZ30K1-62 $\mu \mathrm{m}$, (c) NZ30K05-105 $\mu \mathrm{m},(d)$ NZ30K03-172 $\mu \mathrm{m}$, (e) NZ30K01-1018 $\mu \mathrm{m}$, and (f) NZ30-1526 $\mu \mathrm{m}$.

(NZ30K-T4) samples vary from 49 to $90 \mathrm{MPa}$ and the ratio of $\sigma_{\mathrm{f}} / \sigma_{0.2}$ changes from 0.99 to 1.49 . For the fully T6-treated specimens, however, the fatigue strength varies between 63 and $100 \mathrm{MPa}$ and the $\left(\sigma_{\mathrm{f}} / \sigma_{0.2}\right)$ ratio decreases to about 0.64 to 0.71 , particularly for the high
Zr-containing samples. It can also be seen that the $\sigma_{\mathrm{f}} / \sigma_{0.2}$ ratios for both $\mathrm{T} 4-$ and T6-PA-treated alloys decrease with the decreasing grain size (in another word, with the increasing yield strength). A significant decrease in fatigue strength to yield strength ratios is observed 
Table III. Tensile Properties of the NZ30K Alloy with Different Grain Sizes

\begin{tabular}{lccccccc}
\hline \multirow{2}{*}{ Properties } & & \multicolumn{5}{c}{ Alloys } \\
\cline { 3 - 7 } & Heat Treatments & NZ30 & NZ30K01 & NZ30K03 & NZ30K05 & NZ30K1 & NZ30K2 \\
\hline YS (MPa) & T4 & 32.8 & 40.2 & 69 & 73.5 & 81.2 & 91 \\
& T6-PA & 48 & 70.4 & 111.7 & 127.6 & 145.1 & 156.4 \\
UTS (MPa) & T4 & 72.5 & 95.7 & 173.9 & 176 & 190 \\
Elongation (pct) & T6-PA & 107 & 125.8 & 240.3 & 256.1 & 284.3 & 290.5 \\
& T4 & 16 & 14.5 & 10.4 & 10.5 & 9.1 & 8.2 \\
\hline
\end{tabular}

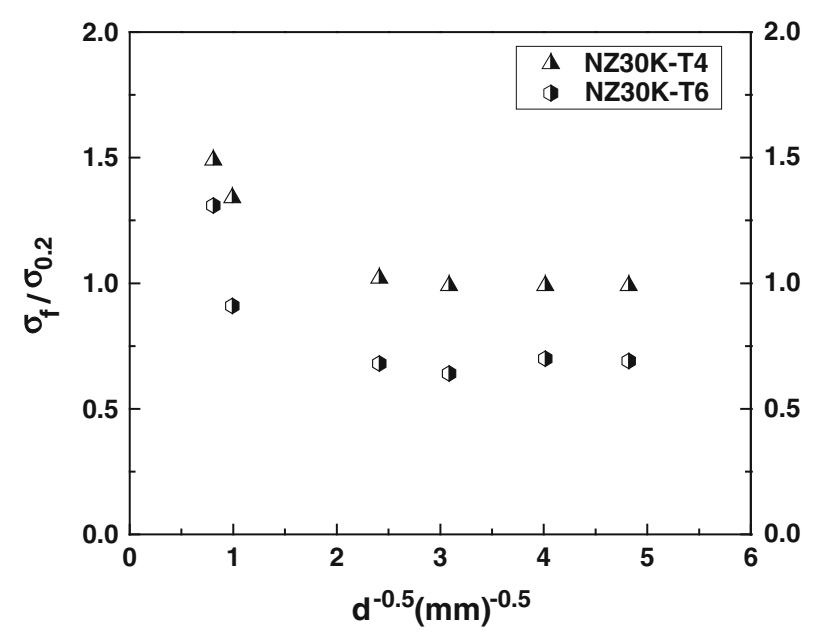

Fig. 8-The ratios of fatigue strength to yield strength, as a function of grain sizes for the NZ30K alloy, both T4 and T6 conditions.

when the grain size decreases to about $170 \mu \mathrm{m}$. A further decrease in grain size below $170 \mu \mathrm{m}$ does not apparently reduce the fatigue strength to yield strength ratio.

Figure 9 shows the overall influence of grain size on fatigue strength in both T4 and T6 heat-treated conditions. Reducing grain size increases fatigue strength, particularly when the grain size is larger than $100 \mu \mathrm{m}$. The increased homogeneity of deformation observed for the fine-grained NZ30K alloy resulted in a considerable improvement in ductility and HCF resistance when compared with the coarse-grained NZ30K alloy. The specimens with the smallest grain size $(\sim 3 \mu \mathrm{m})$ exhibited the highest fatigue strength: $\sim 90 \mathrm{MPa}$ in T4 condition and $\sim 100 \mathrm{MPa}$ in T6 condition. The fatigue strengths were increased by 83 pct (T4) and 59 pct (T6) compared with the coarse-grained alloy with a grain size of about $1500 \mu \mathrm{m}$.

The dependence of fatigue strength $\left(\sigma_{\mathrm{f}}\right)$ on average grain size $(d)$ can be described by $\sigma_{\mathrm{f}}=\sigma_{0}+K_{\mathrm{f}} d^{-1 / 2}$, where $\sigma_{0}$ is the fatigue strength of a single crystal of the material. ${ }^{[12,13]}$ The slope $K_{\mathrm{f}}$, called the Hall-Petch (H-P) strength coefficient, depends on the orientation relation between the interacting grains as well as the critical shear stresses of the activated deformation modes in both grains. With the best fit of the testing data in Figure 9, the relationship between fatigue strength and grain sizes can be expressed as

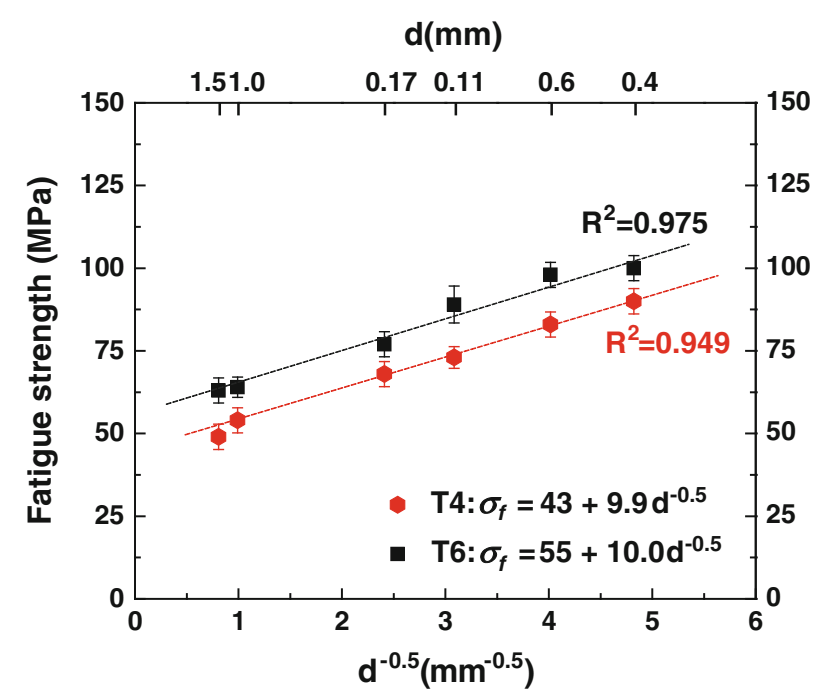

Fig. 9-The fatigue properties of the NZ30K alloy as a function of grain sizes, both $\mathrm{T} 4$ and $\mathrm{T} 6$ conditions.

$$
\begin{aligned}
& \sigma_{\mathrm{f}}(T 4) \approx 9.9\left(d^{-0.5}\right)+43, \quad \text { for T4 condition } \\
& \sigma_{\mathrm{f}}(\mathrm{T} 6) \approx 10.0\left(d^{-0.5}\right)+55 \quad \text { for T6 condition. }
\end{aligned}
$$

\section{Effect of Heat Treatment on the Fatigue Properties of NZ30K1 Alloy with Nominal Composition of $\mathrm{Mg}-3 \mathrm{Nd}-0.2 \mathrm{Zn}-1 \mathrm{Zr}$}

The stress-life fatigue data of the NZ30K1 (actual composition: $M g-2.96 \mathrm{Nd}-0.18 \mathrm{Zn}-0.45 \mathrm{Zr}$ ) alloy (grain size: $\sim 60 \mu \mathrm{m})$ in the as-cast and different heat treatment conditions are shown in Figure 10. The results for AZ91D-T6 alloy are also included in Figure 10(c) for comparison. Table IV includes the tensile properties of the NZ30K1 alloy for similar heat treatment conditions.

The fatigue strength (at $10^{7}$ cycles) and yield strength of the NZ30K1 alloy in the as-cast and different heat treatment conditions are correlated as the ratio of fatigue strength/yield strength $\left(\sigma_{\mathrm{f}} / \sigma_{0.2}\right)$, as shown in Figure 11. The results indicate that the fatigue strength and the $\sigma_{\mathrm{f}} / \sigma_{0.2}$ ratio of the alloy after solution treatment are slightly higher than those of the as-cast alloy. A significant improvement of the fatigue strength and particularly yield strength (a reduction of the $\sigma_{\mathrm{f}} / \sigma_{0.2}$ 


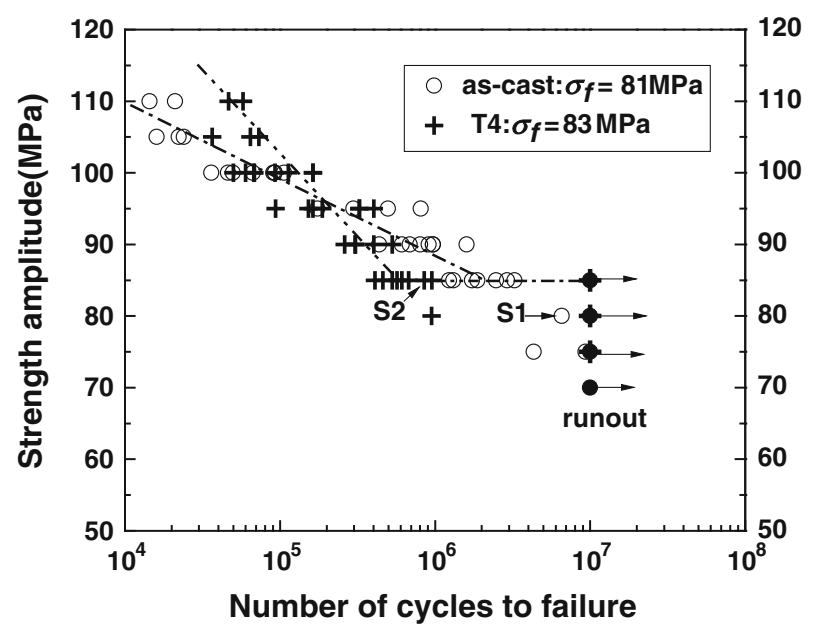

(a)

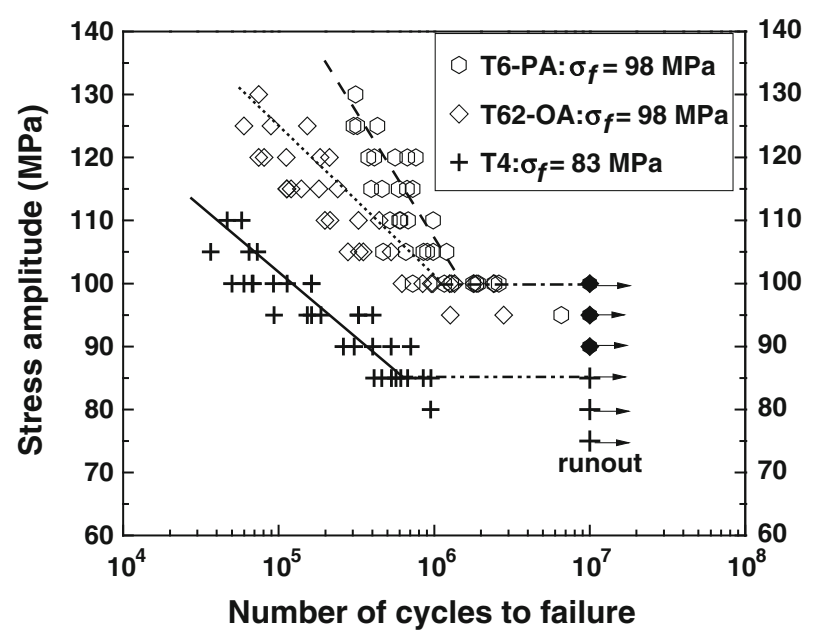

(b)

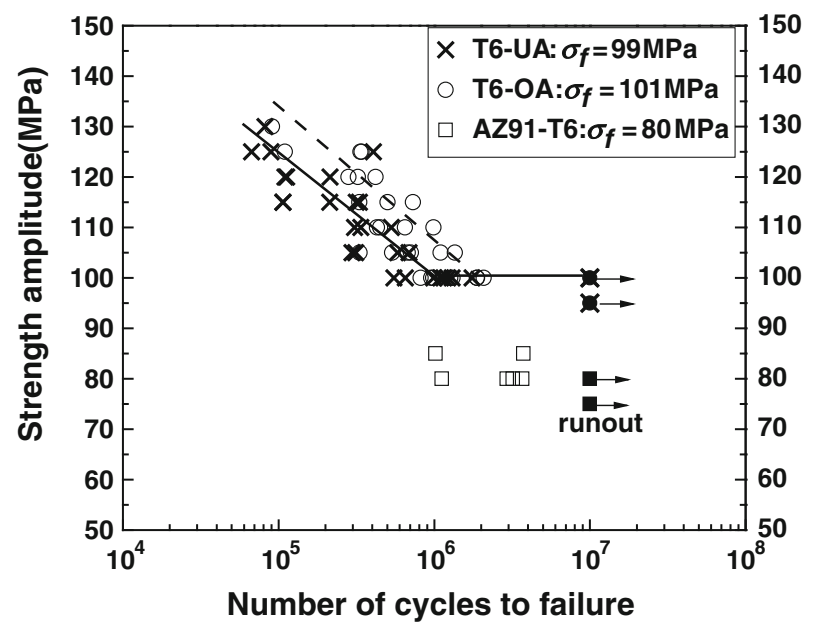

(c)

Fig. 10-Stress-life curves of NZ30K1 alloys (grain size: $\sim 60 \mu \mathrm{m}$ ) under as-cast and different heat treatment conditions: $(a)$ as-cast and T4; (b) T4, T6-PA, and T62-OA; and (c) T6-UA and T6-OA. The data of AZ91-T6 alloy are also included in the (c) for comparison.
Table IV. Tensile Properties of the NZ30K1 Alloy Under Different Heat Treatment Conditions

\begin{tabular}{lccrrrr}
\hline & \multicolumn{5}{c}{ Heat Treatments } \\
\cline { 2 - 7 } Properties & As-Cast & T4 & T6-UA T6-PA T6-OA T62-OA \\
\hline YS (MPa) & 91.2 & 81.2 & 138.6 & 145.1 & 150.1 & 140.7 \\
UTS (MPa) & 179 & 190 & 265.1 & 284.3 & 284.1 & 267.4 \\
Elongation (pct) & 9.7 & 14.5 & 6.6 & 8.8 & 7.3 & 12.9 \\
\hline
\end{tabular}

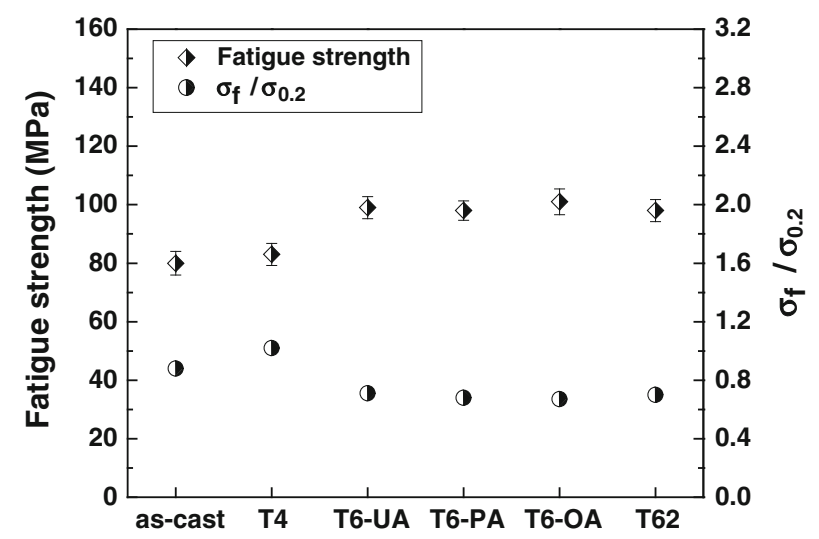

Fig. 11-Fatigue strength and the ratio of fatigue strength to yield strength $\left(\sigma_{\mathrm{f}} / \sigma_{0.2}\right)$ of the NZ30K1 (Mg-3Nd-0.2Zn-1Zr) alloys (grain size: $\sim 60 \mu \mathrm{m}$ ) with different heat treatment conditions.

ratio) is observed after aging hardening, although the fatigue strength and the $\sigma_{\mathrm{f}} / \sigma_{0.2}$ ratios do not show considerable differences among the various aging treatment conditions studied. Over the range of various aging conditions studied, the fatigue strength of the NZ30K1 alloy was $99 \pm 5 \mathrm{MPa}$, which represents an approximate 25 pct increase compared with the as-cast alloy and the AZ91D-T6 alloy $\left(\sigma_{\mathrm{f}} \approx 80 \mathrm{MPa}\right)$. The fatigue strength of the chilled NZ30K1-T6 alloy in the sand casting engine block is also similar to that of the lost foam cast aluminum alloy A319 (also $100 \mathrm{MPa}$ ), ${ }^{[14]}$ which is currently used in many producing GM engine blocks.

Figures 12 and 13 show fatigue failure probability of the samples as a function of fatigue life in natural logarithm Weibull plots. A detailed description of Weibull statistics and the procedure to convert fatigue data into a Weibull plot has been given in Reference 3. The fatigue life data $\left(N_{\mathrm{f}}\right)$ were ranked and ordered from the shortest to the longest, with each being assigned a probability of failure $(\mathrm{Fw})$ based on its rank, $j$, as follows:

$$
\mathrm{FW}_{\mathrm{W}}=(j-0.5) / n,
$$

where $n$ is the total number of fatigue data points. The failure probability $\mathrm{Fw}$ and fatigue life data $\left(N_{\mathrm{f}}\right)$ were then converted into $\ln \ln \left[1 /\left(1-\mathrm{Fw}\left(N_{\mathrm{f}}\right)\right)\right]$ and $\ln \left(N_{\mathrm{f}}\right)$, respectively. 


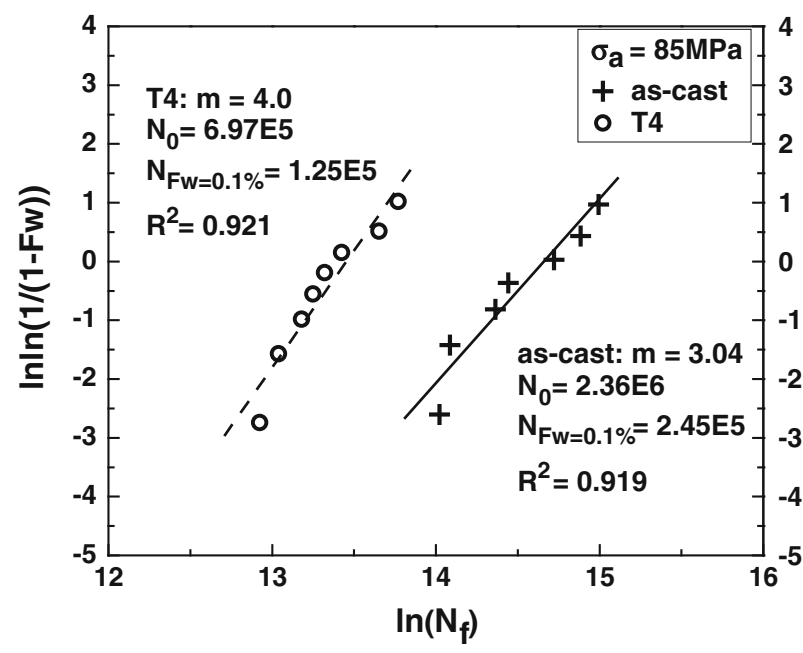

(a)

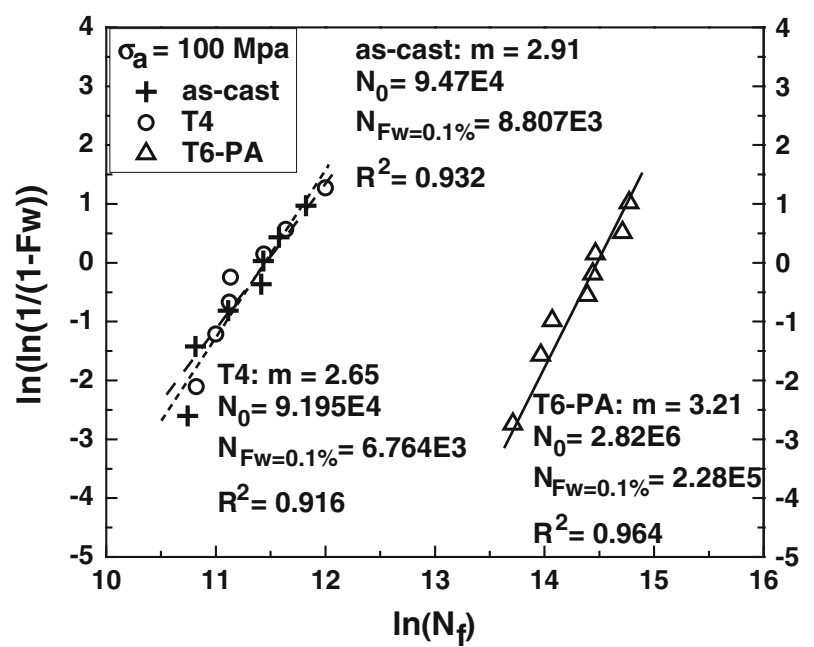

(b)

Fig. 12-Two-parameter Weibull plot for fatigue life data of the NZ30K1 alloy in as-cast and different heat treatment conditions: (a) as-cast and T4, the specimens were tested at a stress amplitude of $85 \mathrm{MPa} ;(b)$ as-cast, T4, and T6-PA, the specimens were tested at a stress amplitude of $100 \mathrm{MPa} . N_{0}$ is the characteristic fatigue life, $N_{\mathrm{FW}}$ is the predicted fatigue life at 0.1 pct failure probability, and $m$ is the Weibull modulus.

The specimens of the as-cast and T4 alloys were tested at the stress amplitude of $85 \mathrm{MPa}$, and the fatigue data points were also plotted linearly, as shown in Figure 12(a). As predicted by the Weibull statistics, the characteristic fatigue life $\left(N_{0}=2.36\right.$ E6 cycles $)$ of the as-cast alloy is three times longer than that of the T4-treated alloy ( $N_{0}=6.97 \mathrm{E} 5$ cycles). At a failure probability of 0.1 pct, the predicted fatigue lives $\left(N_{\mathrm{Fw}}\right)$ for the as-cast and the T4-treated alloys are 1.25 E5 and 2.25 E5 cycles, respectively. For the as-cast, solid solution treatment, and four aged heat treatment alloys, the specimens were tested at a stress amplitude of $100 \mathrm{MPa}$, and the fatigue data points all plot linearly as shown in Figures 12(b) and 13. As predicted by the Weibull statistics, the characteristic fatigue life for the T6-PA-treated alloy is $2.82 \mathrm{E} 6$ cycles which is about 30 times longer than those for the as-cast and T4-treated

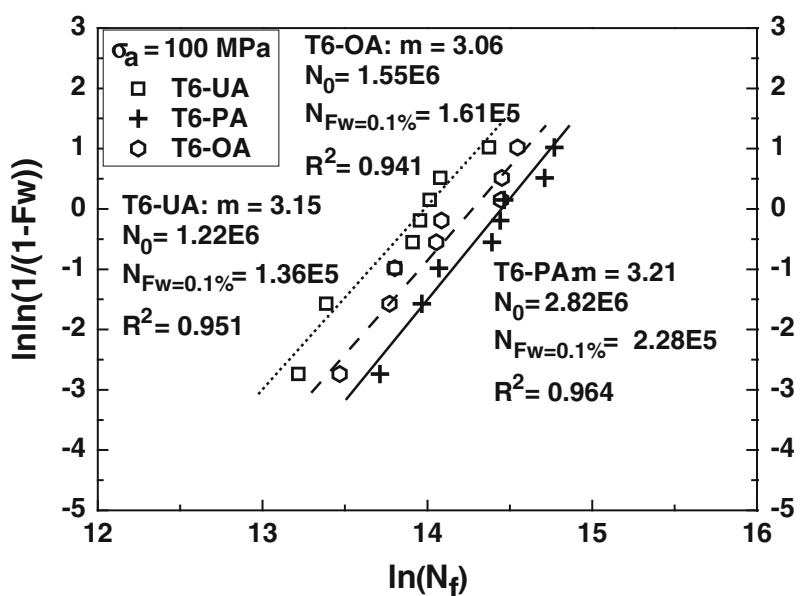

(a)

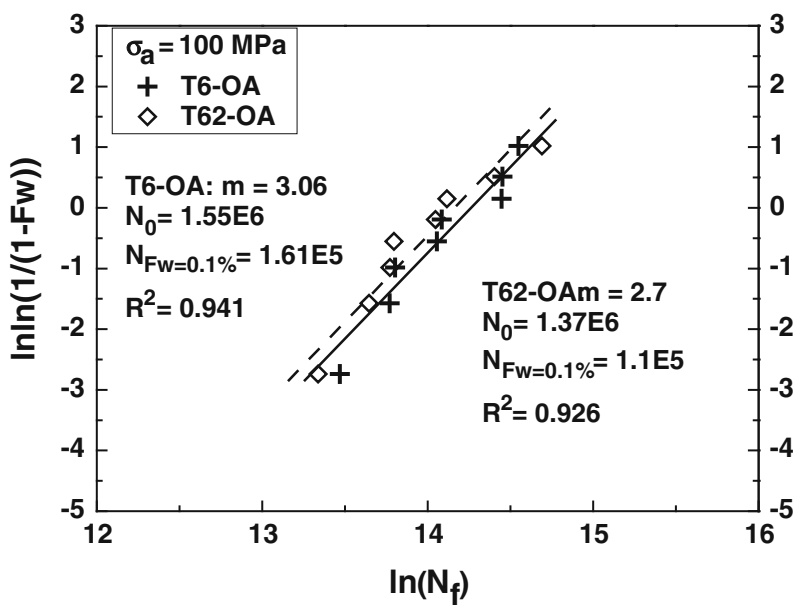

(b)

Fig. 13-Two-parameter Weibull plot for fatigue life data of the NZ30K1 alloy under different aging treatment conditions: (a) T6-UA, T6-PA, and T6-OA, the specimens were tested at a stress amplitude of $100 \mathrm{MPa}$; (b) T6-OA and T62-OA, the specimens were tested at a stress amplitude of $100 \mathrm{MPa}$.

alloys (Figure 12(b)). The characteristic fatigue life for the T6-PA-treated alloy is about 1.3 to 1.5 times longer than those for the other aging treated alloys (Figure 13). However, no significant difference can be seen among the T62-OA (the characteristic fatigue life of 1.37 E6 cycles, the predicted fatigue life of $1.1 \mathrm{E} 5$ cycles at 0.1 pct failure rate), the T6-UA (the characteristic fatigue life of 1.22 E6 cycles, the predicted fatigue life of $1.36 \mathrm{E} 5$ cycles at 0.1 pct failure rate), and the T6-OA (the characteristic fatigue life of 1.55 E6 cycles, the predicted fatigue life of $1.61 \mathrm{E} 5$ cycles at 0.1 pct failure rate) treated alloys. Different aging treatments do not significantly reduce the scatter in the fatigue life either. The Weibull modulus ( $m$ value) ranges from 2.7 to 3.2 for the alloys with different aging conditions.

\section{Fatigue Fracture Behavior}

In nearly all as-cast samples evaluated (an example shown in Figure 14), fatigue cracks mainly originated from the sample-free surfaces with multiple crack 

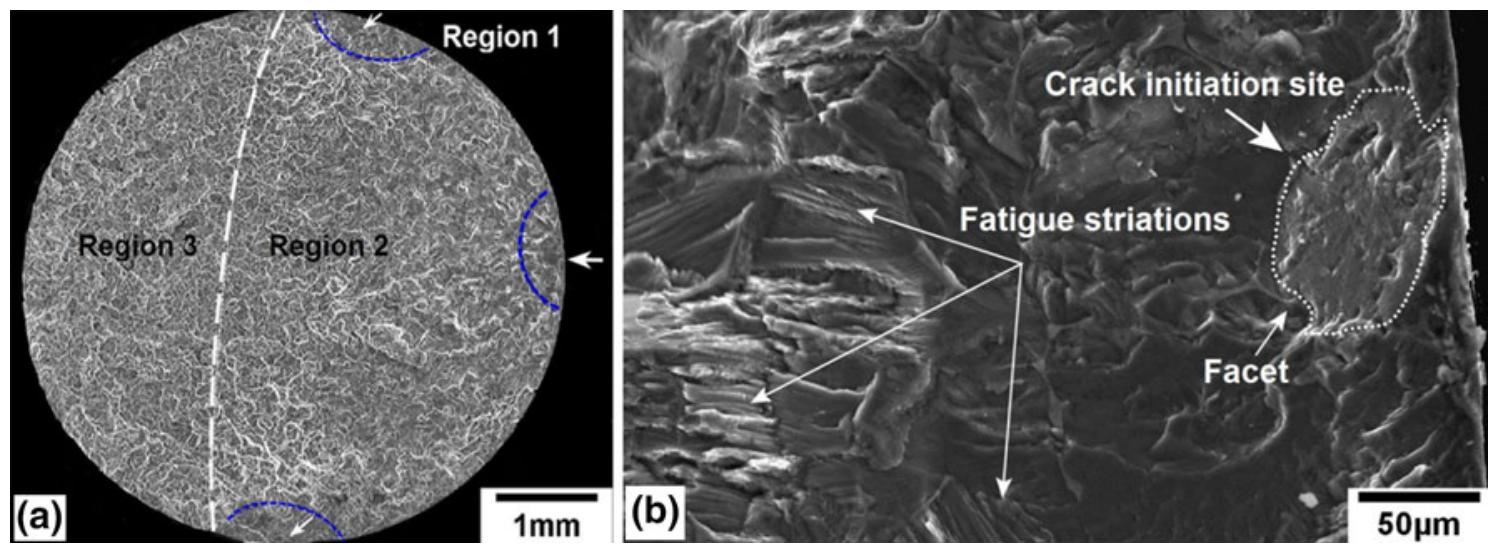

Fig. 14 (a) Overall fracture surface of the as-cast NZ30K1 alloy. The sample S1 was fatigue tested at stress amplitude of $80 \mathrm{MPa}$, and the number of cycles to failure is about $6.5 \times 10^{6}$ cycles. (b) High magnification image showing crack initiation in the as-cast NZ30K1 alloy.
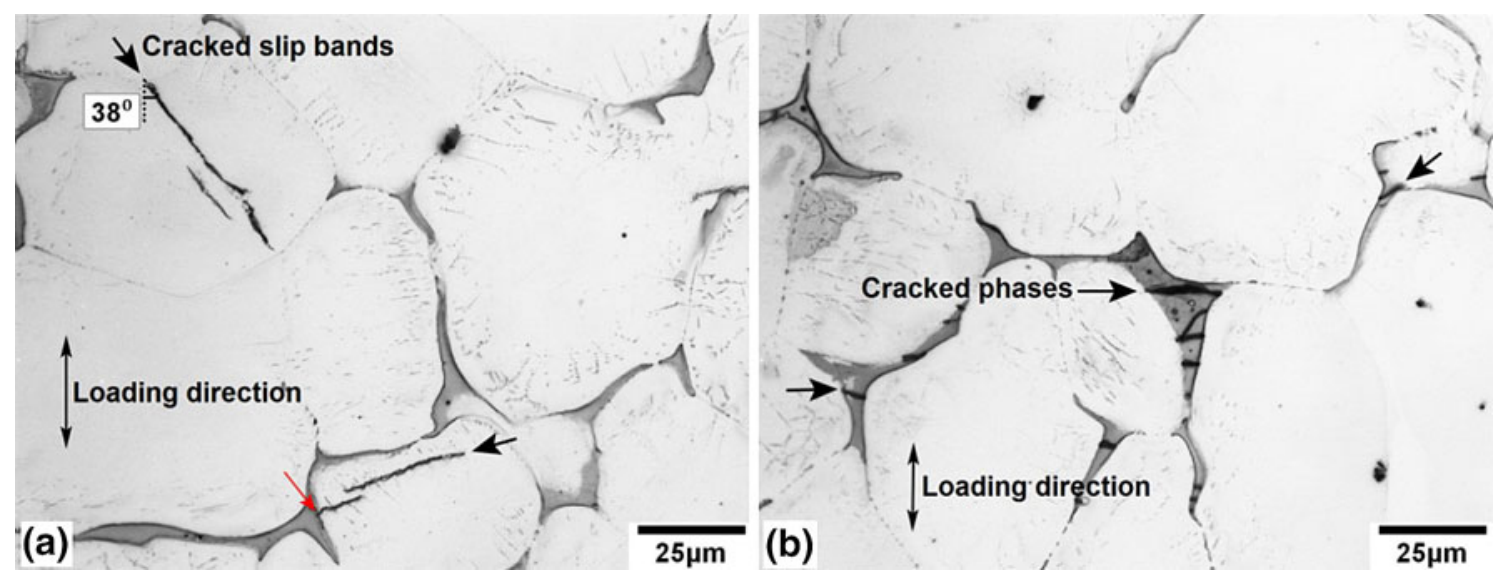

Fig. 15 - Optical images of the specimen section parallel to the gage length beneath the fracture surface of sample S1: (a) secondary cracks forming along slip bands in Region 2 and (b) secondary cracks forming at the eutectic phase particles in Region 3.

origins (it should be noted that these crack initiations are not related to casting flaws), marked by the arrows in Figure 14(a). This is because the surfaces experience the maximum alternate tensile and compressive stress during rotating bend load fatigue. Microplasticity, due to local slip within grains, can occur at nominal stresses much lower than the tensile and compressive yield stress of the material. The fracture surfaces typically have three distinct regions: Region 1 (crack initiation region), Region 2 (crack growth region), and Region 3 (overloading region) (Figure 14(a)). A closeup of Region 1 of the crack nucleation site for the as-cast alloy shows that the fatigue crack initiates at the isolated facet of the cleavage plane (Figure 14(b)). The large facet as crack initiation site is on the order of the grain size in the as-cast alloy, indicating that fatigue failure originates mainly from local shearing near the specimen-free surfaces. The local shearing can easily occur along the weakest cleavage plane of a grain once localized microdamage from PSBs, extrusions, or intrusions is formed. In the crack propagation region (Region 2), serrated fatigue striations are observed in most samples indicating typical cyclic crack growth (opening) and retention (close) during fatigue damage (Figure 14(b)). The presence of striations is evidence that a crack was created by fatigue crack propagation. The micrographs taken from the section plane parallel to the gage length beneath the fracture surface, in Figure 15, also show that secondary cracks are formed mainly along slip bands within individual grains in Regions 1 and 2.

In solution (T4)-treated fatigue specimens, fatigue crack initiation from the specimen surfaces was also observed and shown in Figure 16(a). It is also easily seen that small amounts of deformation twins have formed near the crack initiation areas (Region 1) and secondary cracks have formed along the twin bands (Figure 16(b)). Moreover, in the crack propagation region (Region 2), deformation twins are also clearly revealed (Figure 16(c)). It is, therefore, believed that twinning may play an important role in fatigue crack initiation and propagation in the NZ30K-T4 alloy.

Figure 17 shows typical fracture surfaces of T6-PAtreated specimens with large $(\mathrm{S} 3,1526 \mu \mathrm{m})$ and small (S4, $62 \mu \mathrm{m})$ grain sizes. The microstructures near the crack initiation areas of the specimens $\mathrm{S} 3$ and $\mathrm{S} 4$ are also shown in Figures 17(c) and (d). It is seen that fatigue failure originates mainly from local shearing near the 

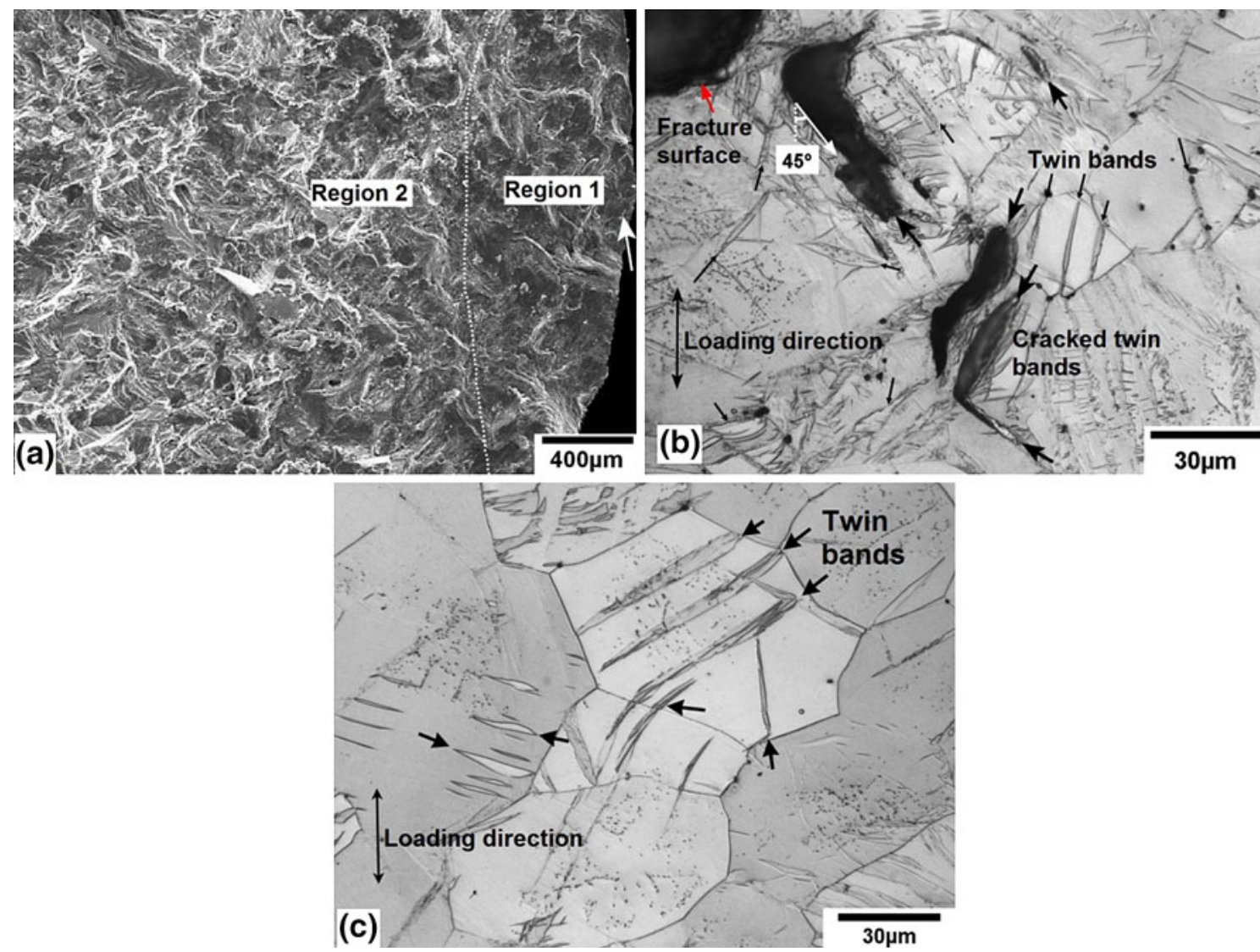

Fig. 16 - (a) SEM image showing crack initiation in the T4-treated NZ30K1 alloy (sample S2: failed after $8.5 \times 10^{5}$ cycles at 85 MPa). Optical images of the specimen section parallel to the gage length beneath the fracture surface of sample S2: (b) Region 1 and $(c)$ Region 2.

specimen-free surfaces in both fine-grained and coarsegrained samples. Compared with the NZ30K-T4 alloy, however, less twinning is observed in both T6-treated coarse-grained S3 and fine-grained S4 specimens during fatigue testing (Figures 17(c) and (d)). In T6-treated NZ30K alloy samples, as twining deformation hardly occurs due to the strong suppression effect of precipitates in grains, ${ }^{[15,16]}$ irreversible dislocation glides under cyclic loading leading to the development of persistent slip bands (PSBs), extrusion, and intrusions in surface grains ${ }^{[17-20]}$ which are optimally oriented for slip. Small microcracks were noted to form along slip bands (Figures 17(c) and (d)), which contribute to the final step in the fatigue crack initiation process. Similar results are also obtained for samples with different aging conditions.

\section{DISCUSSION}

The fatigue strength of NZ30K cast magnesium alloy is generally determined by the existence of casting flaws such as porosity and inclusions, which is consistent with that noted in other casting alloys. In the absence of these flaws, the fatigue strength is mainly influenced by grain size, second-phase particles, and the matrix strength (i.e., solution treatment and precipitation hardening).

\section{A. Effect of Grain Size}

The reduced fatigue strength with increasing grain size can be attributed to the combined effect of increased nanoscale defect probability within an individual grain, increased initial crack sizes, and decreased crack growth resistance in the coarse-grained materials. Increasing grain size increases the volume of an individual grain and thus the total number of nanoscale defects within the grain, which during cyclic loading lead to an increased probability of localized damage (slip bands or twinning) and thus the probability of crack initiation in a grain. Once the localized damage, like slip bands or twinning, occurs within a grain, it can quickly propagate across the whole grain by flat cleavage mode and stop at the grain boundary. Continuous cyclic loading leads to the formation of fatigue cracking in the localized damage areas such as slip bands and sub-grain boundaries. This effect can be appreciated by the observation of fatigue crack initiation and propagation paths in the various fatigue samples.

Figure 18 shows the main crack growth paths in the T6-treated NZ30K alloy with coarse- and fine-grained structures. The high magnification images of Figure 18 are shown in Figure 19 where local yielding can be appreciated from the slip bands as observed in Figure 19. The coarse-grained material shows more 

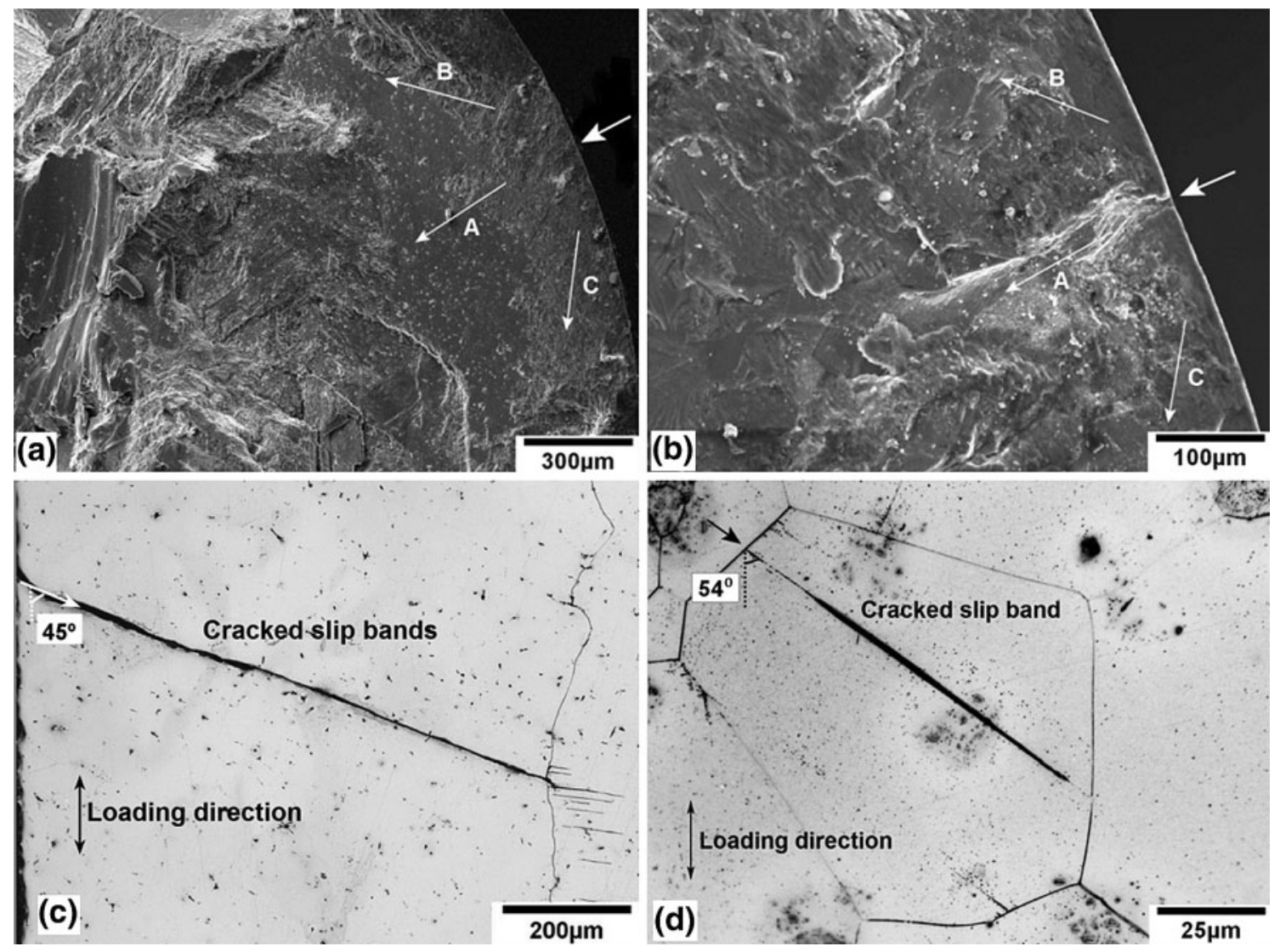

Fig. 17-SEM images showing crack initiation in the NZ30K-T6-PA alloy: (a) coarse grain-S3-1526 $\mu \mathrm{m}$ (failed after $9.5 \times 10^{5}$ cycles at $65 \mathrm{MPa}$ ); (b) fine grain - S4-62 $\mu \mathrm{m}$ (failed after $1.9 \times 10^{6}$ cycles at $100 \mathrm{MPa}$ ). Optical images of the specimen section parallel to the gage length beneath the fracture surface of $(c)$ sample S3 and $(d)$ sample S4 (Region 1).
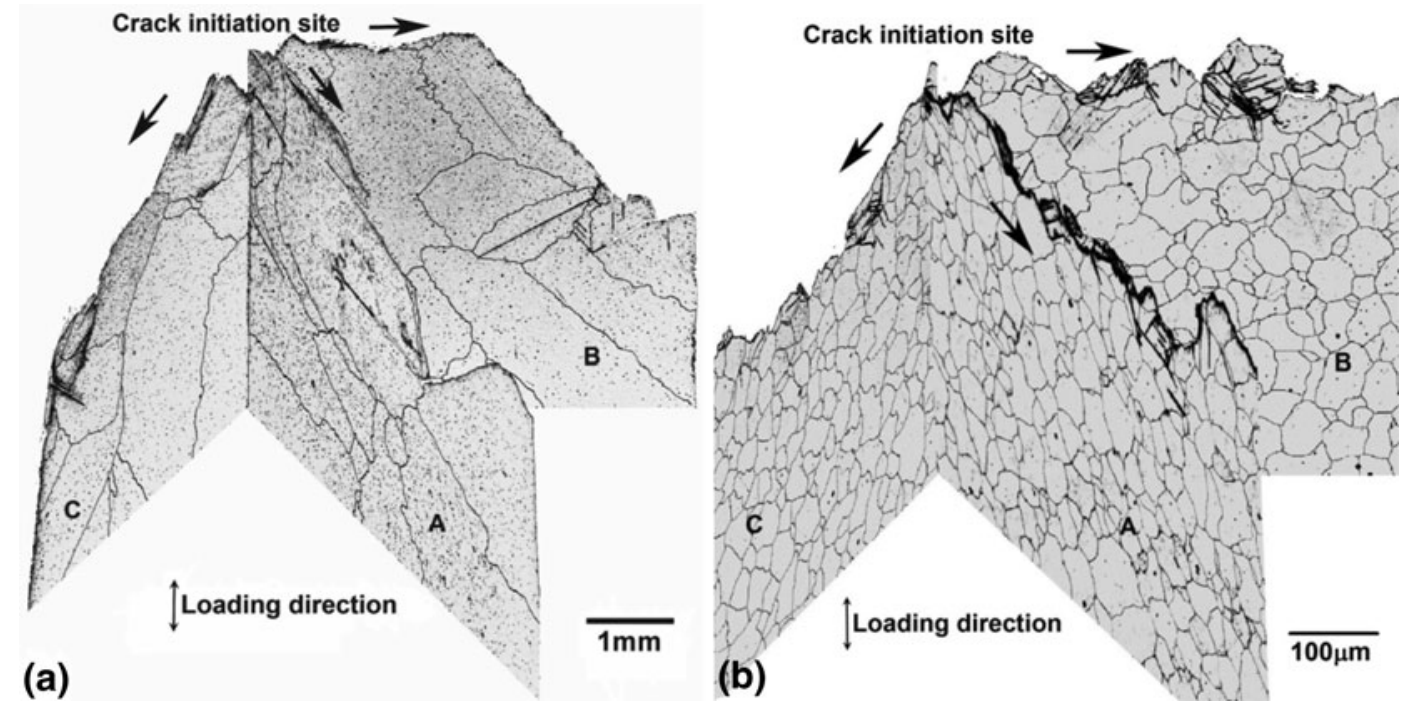

Fig. 18-Main fatigue crack growth path in the T6-treated NZ30K alloy: (a) coarse grain-S3 (failed after $9.5 \times 10^{5}$ cycles at $65 \mathrm{MPa}$ ); $($ b) fine grain-S4 (failed after $1.9 \times 10^{6}$ cycles at $100 \mathrm{MPa}$ ). The way in which observation directions were obtained is shown in Figs. 3 and 17.

and also longer slip bands in the individual grains compared with the fine-grained sample. Slip can take place only on certain crystallographic planes within a grain, while slip under an applied load is not simply reversed when the load is removed. Under fatigue loading, reverse slip takes place on nearby planes leading to the development of intrusions and extrusions, particularly near the specimen-free surfaces. Eventually, surface cracks are produced under these small amounts of reverse plastic strain. It is believed that slip bands are 

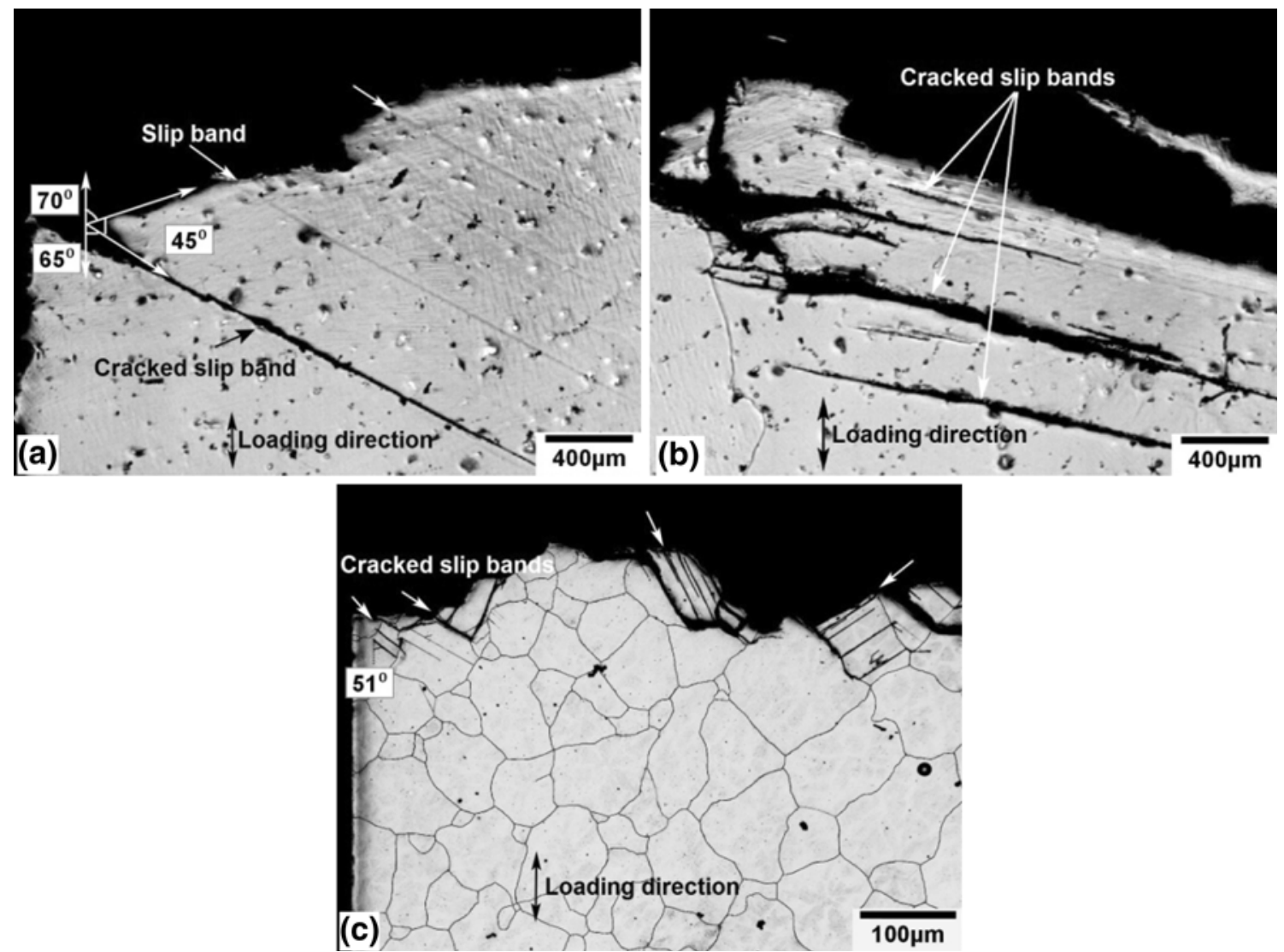

Fig. 19-High magnification images of Fig. 18. Coarse grain-S3: (a) Region 1, (b) Region 2; fine grain-S4: (c) Regions 1 and 2.

formed through the $\{0001\}\langle 11-20\rangle$ basal slip system, which has been reported by Marrow et al. ${ }^{[21]}$ from their EBSD analysis and Yang et al. ${ }^{[22]}$ from their TEM work. Therefore, it means that the coarse-grained sample will form longer initial crack sizes (about equal to grain size) compared with the fine-grained sample, after undergoing similar cyclic loading numbers. This suggests that the coarse-grained sample has lower crack initiation resistance than the fine-grained sample.

Non-basal slip systems can also be activated during fatigue testing, ${ }^{[23]}$ as shown in Figure 19(a), although the CRSS for prismatic slip is about 100 times higher than that for basal slip. ${ }^{[24,25]}$ The $\mathrm{Nd}$ addition in $\mathrm{Mg}$ alloy can increase the activation of non-basal dislocations, and $0.2 \mathrm{pct} \mathrm{Zn}$ addition further enhances the activation effects. $^{[26]}$

In addition to an increased initial crack size (similar to the grain size) in the coarse-grained material, the crack growth resistance is also reduced significantly with increasing grain size. In high cycle fatigue, the crack can quickly grow within a grain by shearing along the slip bands, but it stops at grain boundaries. Since the crack will not grow until the slip bands are activated in neighboring grains, the fatigue crack is more tortuous in fine-grained samples due to the increased crack retardation and deflection from the grain boundaries. As shown in Figures 19(b) and (c), the fatigue cracks in Region 2 of both the coarse-grained and fine-grained NZ30K-T6-PA alloys tend to grow along the slip bands and cut straight across the grains. Many microcracks form from slip bands ahead of the main crack front, and the slip bands provide an easy path for crack propagation. Similar results are also obtained for the T4-treated samples, in which the fatigue cracks tend to propagate along twin bands.

\section{B. Effect of Second-Phase Particles}

In the as-cast $\mathrm{NZ30K}$ alloy, the $\mathrm{Mg}$ matrix is relatively soft and the interaction among dislocations, eutectic phase particles, and grain boundaries dominates the hardening and thus the local damage. ${ }^{[27-29]}$ Slip bands can be effectively retarded by the eutectic $\beta$-phases and/or grain boundaries from which high stress concentrations can be easily induced. Because of the low stress intensity factor and the small crack tip plastic zone size in Regions 1 and 2, the eutectic particles fail mainly by debonding (Figure 15(a)). In Region 3, however, the microcracks form mainly by cracking of the eutectic compounds (Figure 15(b)) due to the presence of large plastic strain during overloading. This indicates that with an increase of crack tip driving force in the overloading stage, the increased stress concentration near the grain boundaries not only destroys the strong bonding of $\beta$-phase $/ \alpha-\mathrm{Mg}$ matrix interfaces but also cracks the eutectic particles. As a result, slip band shearing and/or eutectic particle debonding/cracking provides an easy path for crack propagation. Thus, the 
fracture mode in Regions 1 and 2 is usually transgranular, while the fatigue cracks in Region 3 mainly propagate in an intergranular mode. A similar result has been reported in Reference 30.

For the solution-treated NZ30K1 (T4) alloy (grain size: $\sim 60 \mu \mathrm{m}$ ), the microstructure consists of soft matrix (supersaturated solid solution) and a very small amount of undissolved eutectic phase particles at the grain boundaries. A majority of the as-cast $\mathrm{Nd}$-containing eutectic phase particles on the grain boundaries are dissolved in the $\alpha$ magnesium matrix during solution treatment. Although solute Nd atoms may interact with dislocations and influence the threshold stress for dislocation glide, local plastic deformation and twinning can easily occur during fatigue because of the very low matrix strength of the solution-treated NZ30K alloy. ${ }^{[31]}$ Deformation-induced twins readily form in the plastic zone from the compressive stress during rotating bending and then open up to form a microscopic crack from the tensile stress. ${ }^{[32]}$ For the solution-treated (T4) alloys, cyclic deformation and damage irreversibly caused by twinning are thus the crucial factors influencing fatigue properties. Twinning-related fatigue crack initiation has also been reported by Yang et al. ${ }^{[31]}$

\section{Effect of Matrix Strength}

The present experimental results show that the fatigue strength of the T6-treated NZ30K1 alloy is about $100 \mathrm{MPa}$, about $25 \mathrm{pct}$ higher than that of the T4-treated alloy. Since the grain size of the NZ30K1T6 alloy and the NZ30K1-T4 alloy is similar (grain size: $\sim 60 \mu \mathrm{m})$, the improvement in fatigue strength in the T6-treated alloy can only be attributed to matrix strength. Different contributions to the fatigue strength need to be considered to understand the effect of matrix strength, particularly between T4 and T6 heat treatments on the fatigue strength of the NZ30K alloys. In the T4-treated alloy, the solid solution strengthening is the major mechanism and generally low. ${ }^{[33,34]}$ After aging treatment, however, precipitation hardening $\left(\sigma_{\mathrm{ppt}}\right)$ is the major strengthening mechanism, which is generally much stronger than solid solution strengthening. ${ }^{[7,35,36]}$ The increased matrix strength reduces the number and size of local plastic deformation zones in the material, ${ }^{[4]}$ which decreases the possibility of forming microcracks in front of the fatigue crack due to a reduced interaction of dislocations with grain boundaries. Increasing matrix strength also increases the matrix resistance to dislocation movement and formation of slip bands as well as suppresses the twin bands by precipitates. As a result, increasing matrix strength decreases not only crack initiation but also crack growth rate.

Among the age-hardened alloy samples, the influence of different aging conditions on fatigue properties is complex. In the under-aged and peak-aged samples, fine and dense $\beta^{\prime \prime}$ precipitates coherent with the $\alpha$ magnesium matrix tend to lead to an inhomogeneous distribution of slip bands and, thus, less elongation due to the mechanism of particle shearing. The small and dense $\beta^{\prime \prime}$ precipitates pin dislocations, resulting in an additional increase of the threshold stress for basal slip. The

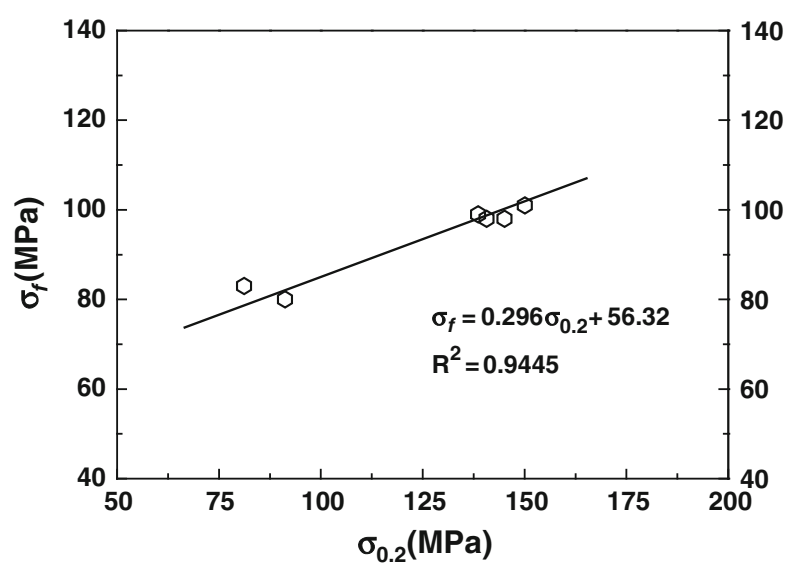

Fig. 20-The relationship between the yield strength $\sigma_{0.2}$ and the fatigue strength $\sigma_{\mathrm{f}}$ of the NZ30K1 alloys (grain size: $60 \mu \mathrm{m}$ ) in different heat treatment conditions.

increased threshold stress requires high stress amplitude that is necessary for the formation of slip bands and thus governs the resistance to fatigue crack nucleation of the alloy. ${ }^{[35]}$ In the over-aged alloys such as NZ30K-T62 [over-aged at $523 \mathrm{~K}\left(250{ }^{\circ} \mathrm{C}\right)$ for 10 hours], $\beta^{\prime}$ precipitates with fcc structure $(a=0.742 \mathrm{~nm})$ are the dominant phase. ${ }^{[7]}$ The semi-coherent or incoherent $\beta^{\prime}$ phase leads to relatively homogenous slip distribution and thus high ductility because of the mechanism of precipitate bypass. The low yield strength in the over-aged alloys decreases the crack initiation life and thus fatigue life particularly at the high stress amplitude in low-cycle fatigue (Figure 10(b)).

Figure 20 shows the relationship between the yield strength $\sigma_{0.2}$ and fatigue strength $\sigma_{\mathrm{f}}$ of the NZ30K1 alloy (grain size: $\sim 60 \mu \mathrm{m}$ ) in the as-cast and different heat treatment conditions. In the absence of casting flaws, the fatigue strength increases with increasing yield strength (matrix strength) of the material according to the following linear relationship:

$$
\sigma_{\mathrm{f}} \approx 0.3\left(\sigma_{0.2}\right)+56.3
$$

\section{CONCLUSIONS}

1. Zirconium $(\mathrm{Zr})$ is an effective grain refiner for the NZ30K (Mg-3Nd-0.2Zn) alloy. Adding about 0.45 wt pct $\mathrm{Zr}$ reduces the average grain size from about $1500 \mu \mathrm{m}$ to about $60 \mu \mathrm{m}$ ( 40 times reduction), resulting in about twice the fatigue strength. The NZ30K (Mg-3Nd-0.2Zn) alloy also shows a linear $\mathrm{H}-\mathrm{P}$ relationship between fatigue strength and grain size.

2. The NZ30K alloy shows significant response to heat treatment, particularly age hardening. Compared with the as-cast alloy, the peak-aged [14 hours at $473 \mathrm{~K}\left(200^{\circ} \mathrm{C}\right)$ ] alloy shows about 25 pet increases in fatigue strength.

3. In the absence of casting flaws, the fatigue failure of NZ30K alloy mainly originated from localized 
shearing near the specimen surfaces during cyclic loading. The threshold stress for basal slip, which is affected by secondary eutectic phase hardening and grain boundary constrains, is noted to control crack initiation, particularly in the as-cast condition.

4. For the T4-treated (solution only) samples, the local shearing is dominated by deformation twinning, while the samples in the T6 (solution and aging treatments) conditions are likely controlled by the interactions between dislocations and fine precipitates in the $\mathrm{Mg}$ matrix. Moreover, the fatigue crack in T4-treated samples tends to propagate along the twin bands, while the cracks propagate along slip bands in the T6-treated ones.

5. The NZ30K alloy, with 0.45 wt pet $\mathrm{Zr}$ addition as grain refiner and in peak-aged $\mathrm{T} 6$ condition [14 hours at $473 \mathrm{~K}\left(200{ }^{\circ} \mathrm{C}\right)$ ], has a fatigue strength of about $100 \mathrm{MPa}$, which is about 25 pct higher than that of commercial AZ91D-T6 alloy and comparable with that of lost foam cast aluminum alloy A319-T6.

\section{ACKNOWLEDGMENTS}

This work was supported by the National Natural Science Foundation of China (Project No. 51201103) and the SJTU-GM Collaborative Research Laboratory jointly established by General Motors Global Research and Development (GM R\&D), Warren, MI, USA, and Shanghai Jiao Tong University (SJTU), Shanghai, China. The authors are grateful to Drs. Yucong Wang and Anil Sachdev of GM and Prof. Wengjiang Ding of SJTU for their support and helpful discussions. The authors would also like to thank Jason Traub, Todd Meitzner, and Robert Kubic of GM R\&D for providing laboratory facilities and their assistance in experiments.

\section{REFERENCES}

1. A.I. Taub, P.E. Krajewski, A.A. Luo, and J.N. Owens: JOM, 2007, vol. 59, pp. 48-57.

2. A.A. Luo: SAE Trans. J. Mater. Manuf., 2005, vol. 114, pp. 41121.

3. Q.G. Wang, D. Apelian, and D.A. Lados: J. Light Met., 2001, vol. 1, pp. 73-84.

4. Q.G. Wang, D. Apelian, and D.A. Lados: J. Light Met., 2001, vol. 1, pp. 85-97.

5. M.F. Horstemeyer, N. Yang, K. Gall, D.L. McDowell, J. Fan, and P.M. Gullett: Acta Mater., 2004, vol. 52, pp. 1327-36.
6. M.D. Chapetti, T. Tagawa, and T. Miyata: Mater. Sci. Eng. A, 2003, vol. 356, pp. 236-44.

7. P.H. Fu, L.M. Peng, H.Y. Jiang, J.W. Chang, and C.Q. Zhai: Mater. Sci. Eng. A, 2008, vol. 486, pp. 183-92.

8. P.H. Fu, L.M. Peng, H.Y. Jiang, L. Ma, and C.Q. Zhai: Mater. Sci. Eng. A, 2008, vol. 496, pp. 177-88.

9. L.L. Rokhlin: Magnesium Alloys Containing Rare Earth Metals, Taylor and Francis, London, 2003, pp. 159-64.

10. "Specification and Verification of Tensile and Fatigue Properties in Cast Components", GM ENGINEERING STANDARDS, Material Specification Metals, GMN7152, Feb. 2002.

11. P.H. Fu, L.M. Peng, H.Y. Jiang, C.Q. Zhai, C.Q. Zhai, X. Gao, and J.F. Nie: Mater. Sci. Forum, 2007, vols. 546-549, pp. 97-100.

12. E.O. Hall: Proc. Phys. Soc. B, 1951, vol. 64, pp. 747-53.

13. J.R. Davis: Aluminum and Aluminum Alloys, ASM, Metals Park, OH, 1993, p. 113.

14. Q.G. Wang and P. Jones: SAE Int. J. Mater. Manuf., 2011, vol. 4, pp. 289-97.

15. J.B. Clark: Acta Metall., 1968, vol. 16, p. 141.

16. C.H. Cáceres, C.J. Davidson, J.R. Griffith, and C.L. Newton: Mater. Sci. Eng. A, 2002, vol. 325, pp. 344-55.

17. H. Mughrabi: Rev. Phys. Appl., 1988, vol. 23, pp. 367-79.

18. S.E. Harvey, P.G. Marsh, and W.W. Gerberich: Acta Metall. Mater., 1994, vol. 42, pp. 3493-3502

19. J. Man, K. Obrtlik, C. Blochwitz, and J. Polak: Acta Mater., 2002, vol. 50 , pp. $3767-80$.

20. J. Polak, J. Man, T. Vystavel, and M. Petrenec: Mater. Sci. Eng. A, 2009, vol. 517, pp. 204-11.

21. T.J. Marrow, A.A. Bin, I.N. Khan, S.M.A. Sim, and S. Torkamani: Mater. Sci. Eng. A, 2004, vol. 419, pp. 387-89.

22. F. Yang, F. Lv, X.M. Yang, S.X. Li, Z.F. Zhang, and Q.D. Wang: Mater. Sci. Eng. A, 2011, vol. 528, pp. 2231-38.

23. J. Koike, T. Kobayashi, T. Mukai, H. Watanabe, M. Suzuki, K. Maruyama, and K. Higashi: Acta Mater., 2003, vol. 51, pp. 2055-65.

24. T. Obara, H. Yoshinea, and S. Morozumi: Acta Metall., 1973, vol. 21 , pp. $845-53$.

25. S.E. Lon, F.J. Humphreys, and S.H. White: Acta Metall., 1982, vol. 30, pp. 1909-19.

26. P.H. Fu, L.M. Peng, J.F. Nie, H.Y. Jiang, L. Ma, and L. Bourgeois: Mater. Sci. Forum, 2011, vol. 690, pp. 230-33.

27. Q.G. Wang: Ph.D. Thesis, The University of Queensland, Brisbane, Australia, 1997.

28. C.H. Cáceres, J.R. Griffiths, and P. Reiner: Acta Mater., 1996, vol. 44 , pp. $15-23$.

29. C.H. Cáceres and J.R. Griffiths: Acta Mater., 1996, vol. 44, pp. $25-33$.

30. D.K. Xu, L. Liu, Y.B. Xu, and E.H. Han: Acta Mater., 2008, vol. 56 , pp. $985-94$

31. F. Yang, S.M. Yin, S.X. Li, and Z.F. Zhang: Mater. Sci. Eng. A, 2008, vol. 491, pp. 131-36.

32. T.S. Shih, W.S. Liu, and Y.J. Chen: Mater. Sci. Eng. A, 2002, vol. 325 , pp. $152-62$.

33. L. Gao, R.S. Chen, and E.H. Han: J. Alloy. Compd., 2009, vol. 481, pp. 379-84.

34. L. Gao, R.S. Chen, and E.H. Han: J. Alloy. Compd., 2009, vol. 472 , pp. $234-40$.

35. J. Dong, W.C. Liu, X. Song, P. Zhang, W.J. Ding, and A.M. Korsunsky: Mater. Sci. Eng. A, 2010, vol. 527, pp. 6053-63.

36. S.M. He, X.Q. Zeng, L.M. Peng, X. Gao, J.F. Nie, and W.J. Ding: J. Alloy. Compd., 2006, vol. 421, pp. 309-13. 